\title{
Shackled High Speed Traders? Latency Reduction and Short Sale Bans
}

\author{
Bidisha Chakrabarty \\ Pamela C. Moulton \\ Roberto Pascual*
}

January 25, 2016

\footnotetext{
* Bidisha Chakrabarty is at Saint Louis University (chakrab@slu.edu); Pamela C. Moulton is at Cornell University (pm388@cornell.edu); and Roberto Pascual is at University of the Balearic Islands, (rpascual@uib.es). We thank Kevin Crotty for useful discussions, David Abad and Catalina Gaebler for data-related help, the Bolsas y Mercados Españoles (BME) for providing data, and Mikel Tapia and Jorge Yzaguirre (Head of Equities \& Derivatives at BME) for insightful comments. Roberto Pascual acknowledges the financial support of the Fundación BBVA and the Spanish DGICYT project ECO20134409-P. The opinions expressed in this paper are those of the authors exclusively.
} 


\title{
Shackled High Speed Traders? Latency Reduction and Short Sale Bans
}

\begin{abstract}
We examine the effects of two juxtaposed events - regulatory short sale bans and exchange efforts to facilitate high-frequency trading (HFT) - on multiple dimensions of market quality. Between 2011 and 2013, the Spanish Stock Exchange (SSE) launched a smart trading platform (SIBE-Smart) and introduced colocation facilities to attract HFT. During this time two short sale bans were imposed on the SSE. Comparing the market before and after these events, we find that while SIBE-Smart attracts some HFT, colocation does not. However, following both of these events, liquidity and price efficiency decline. Colocation, implemented during the second ban, is accompanied by an across-the-board deterioration in market quality. Strikingly, SIBE-Smart, which precedes a ban, also brings significant reductions in market quality. These results are in contrast to existing studies that show increased HFT resulting from technological inducements. We conclude that the beneficial effects of HFT on liquidity and price efficiency are negated in the presence of regulatory restrictions on trading.
\end{abstract}

JEL Classification: G14, L10

Keywords: High-frequency trading; Short sale ban; Colocation; SIBE-Smart 


\section{Introduction}

Technological innovations in the last decade have changed the trading landscape from one dominated by human intermediaries to a latency-reduction race amongst machines. ${ }^{1}$ This new trading paradigm, popularly known as high-frequency trading (HFT), has garnered immense interest from the media, in academia, and among regulators. The debate on whether HFT is a net benefit to investors continues, with evidence pointing to both positive and negative effects on market quality. ${ }^{2}$

This ambiguity about the impact of HFT in modern markets dominated by HFT is a special challenge to regulators and exchanges. Regulators want to ensure that any proposed regulation curbs the undesirable effects of HFT without undoing the benefits. The dilemma is highlighted in a recent statement by Securities and Exchange Commission (SEC) Chair Mary Jo White: "The SEC should not roll back the technology clock or prohibit algorithmic trading, but we are assessing the extent to which specific elements of the computer-driven trading environment may be working against investors rather than for them." ${ }^{, 3}$ At the same time, exchanges that adopt technologies to facilitate modern trading practices must keep in mind that regulations may impact HFTs differently from other traders. Therefore any data-based evidence on

\footnotetext{
${ }^{1}$ Although estimates of the total volume attributable to HFT are not easy to obtain and depend on how exactly HFT is defined, as of 2009 HFT accounted for between $60-73 \%$ of all US equity trading, with that number falling to about $50 \%$ in 2012 and 2013. For a breakdown of HFT volume by year for US equities, see http://tabbforum.com/opinions/high-frequency-trading-an-important-conversation. For the Spanish market, citing BME as their source, Blas, González, and Villanueva (2011) estimate that HFT account for 25-30\% of SSE total volume in 2010. A recent report by the European Securities and Markets Authority (ESMA, 2014) estimates that HFT represent $32 \%$ of value traded, $29 \%$ of trades, and $46 \%$ of orders of the most frequently traded SSE-listed stocks.

${ }^{2}$ Hendershott, Jones, and Menkveld (2011) find that algorithmic trading (of which HFT is a subset) improves market quality by reducing spreads and adverse selection and improving the informativeness of quotes. Hasbrouck and Saar (2013) and Brogaard (2010) also document evidence of lower short-term volatility and better price discovery associated with HFT. Brogaard, Hagströmer, Nordén, and Riordan (2015) find that although colocation provides informational advantages to HFT traders, overall market quality is improved after the introduction of colocation. However, more recent studies also document negative effects of HFT. Boehmer, Fong, and Wu (2015) find that algorithmic trading is detrimental to the market quality of small stocks. Baron, Brogaard, and Kirilenko (2012) show that HFT firms generally do not provide liquidity to markets, and in fact their most profitable trades are the ones that most aggressively take liquidity. Egginton, Van Ness, and Van Ness (2014) point to quote stuffing practices by HFTs. We discuss these and other related research in Section 2.

${ }^{3}$ See full text of speech at http://www.sec.gov/News/Speech/Detail/Speech/1370542004312\#.U86NC_ldWzd
} 
the impact of regulation and technological improvements in modern markets should be of broad interest to regulators as well as to investors who are affected by the rules.

In this study we aim to provide such evidence. Specifically, we examine whether HFTs respond to technological inducements in the presence of trading restrictions, and we study the net effect of the interplay of regulations and technological improvements on market quality. This is an important issue because studies that document the positive effects of HFT on market quality have generally examined markets without regulatory restrictions. We exploit a unique setting that spans the interspersing of two short sale bans with infrastructure upgrades and colocation to induce HFT on the Spanish Stock Exchange (SSE). We conduct multiple event studies with a view to understanding how various dimensions of market quality - liquidity, price efficiency, returns to liquidity provision, and adverse selection - are impacted by the interaction of HFT with short sale restrictions.

Short sale bans are a common tool used by regulators around the world, mostly in times of precipitous price declines. Researchers generally agree that short sale bans have limited efficacy in stemming price falls and lead to a worsening of market quality. However, to the best of our knowledge, whether the effects of short sale bans are alleviated or exacerbated by efforts to increase HFT has not been explicitly tested. Notably, two studies examine the effect of the 2008 short sale ban in the context of HFTs. Brogaard, Hendershott, and Riordan (2014b) study HFT versus non-HFT short selling and use the 2008 ban as an instrument. They find that HFT short sales degrade market quality. Boehmer, Jones, and Zhang (2013) examine the effects of the U.S. short sale ban in 2008. They hypothesize that short sale bans should disproportionately damage liquidity in stocks where HFT firms are more active, but in the absence of 
suitable data, they cannot verify this hypothesis. Furthermore, both of these studies examine the U.S. market at a time when HFT is already a dominant player.

In contrast, our sample comes from the SSE at a time when it has little HFT activity, and we track market quality as the SSE adopts infrastructure upgrades to explicitly attract $\mathrm{HFT}^{4}$ We then examine how regulatory restrictions impede HFT activity, with related effects on market quality. Given the timeline of events on the SSE, we are able to examine whether markets are able to attract HFT with technological inducements in the presence of trading restrictions. Do the positive effects of HFT on market quality overcome the negative impact of short sale bans? Or do HFTs stay away from markets with regulatory restrictions, thereby exacerbating the negative effects of short sale bans? We address these and related questions by analyzing several pre- and post-event windows surrounding the introduction of the smart trading platform SIBESmart, colocation, and the two short sale bans.

We document several findings. First, comparing the periods before and after all of these events (SIBE-Smart, colocation, and the two short sale bans), we find no net increase in HFT activity. Meanwhile liquidity worsens: Dollar depth decreases, spreads increase, and order book elasticity falls. Price efficiency declines as return autocorrelations increase. The SIBE-Smart trading platform introduction, which does not directly coincide with a ban but follows the first ban and precedes the second ban, is actually accompanied by an across-the-board deterioration of all liquidity measures, although it manages to attract a modest increase in HFT activity. In contrast, the colocation event, which is announced during the second short sale ban, is accompanied

\footnotetext{
${ }^{4}$ While direct estimates of HFT activity on the SSE are not available over our sample period, the Comisión Nacional del Mercado de Valores (CNMV) estimates that in 2011, the start of our sample period, the share of some prominent HFT facilitating platforms (e.g., Chi-X, Turquoise, and BATS) in the total trading volume of all Spanish listed stocks ranged from under $1 \%$ to $1.2 \%$. See Table 17 of the CNMV Bulletin, Q2, 2014.
} 
by a reduction in HFT activity and sees significant liquidity and price efficiency declines. This contrasts directly with the results presented in Brogaard, Hagströmer, Nordén, and Riordan (2015), who find that colocation (without any regulatory restrictions) improves overall market depth and reduces spreads.

As expected, the short sale bans result in liquidity declines, with the second ban seeing a steeper reduction in liquidity than the first ban. The sequence of events on the SSE also allows us to isolate the effects of colocation with and without the ban. We find that although the amount of HFT does not increase in either case, liquidity improves with colocation in the absence of a ban.

Taken together, our results indicate that the regulatory restrictions are serious impediments that the technological inducements cannot overcome. HFT does not respond to the smart trading platform and colocation inducements, and the net result is a decline in liquidity and price efficiency. Overall the negative effects of short sale bans prevail. These results, which are in contrast to the beneficial effects of HFT on liquidity and price efficiency documented by earlier studies, indicate that the positive effects of HFT on market quality are countervailed in the presence of regulatory restrictions on trading. Finally, our results underscore the importance of non-U.S. market settings in arriving at conclusions about the effect of regulations and trading technology. There is an emerging body of literature that shows that many of the findings from U.S. markets do not generalize to other countries. We add to this international evidence on HFT, regulations, and market outcomes. ${ }^{5}$

\footnotetext{
${ }^{5}$ Brogaard, Hendershott, Hunt, and Ysusis (2014) find no effect of HFTs on institutional trading costs using a U.K. sample. Korajczyk and Murphy (2015) use a Canadian dataset and find HFTs are less active for large institutional trades. Using Swedish data, van Kervel and Menkveld (2015) find that HFTs initially provide liquidity but then trade with institutional trades.
} 
The remainder of the paper is organized as follows. In Section 2 we present a review of the literature on HFT and short sales. Section 3 describes the institutional details of the SSE and discusses the timeline of events spanned by our sample period. Section 4 discusses the sample selection and market quality metrics, and Section 5 presents our results. Section 6 presents robustness checks, and Section 7 concludes.

\section{HFT and short sale ban background}

\subsection{HFT and market quality}

As technological advances replace old trading systems with newer and faster ones, regulators face the challenge of adapting rulemaking to the new realities of modern markets. In the U.S., the SEC's effort to gauge the impact of HFT on market quality was accelerated by the Flash Crash of 2010, which many blamed on HFT (if not as a trigger, at least as a contributory factor). In March 2014, the SEC released a comprehensive review of the U.S. equity market structure, with half of the study devoted to reviewing the existing evidence on HFT. Around the same time (April 15, 2014), European regulators imposed some of the toughest regulations on high-frequency (HF) traders in the E.U. These new rules include limits to keep price increments for low-priced securities from becoming too small, mandatory tests of trading algorithms, and a requirement that market makers provide liquidity for a minimum number of hours each day. ${ }^{6}$

The U.S. and international evidence on the impact of HFT on market quality is mixed. ${ }^{7}$ Malinova, Park, and Riordan (2014) use data from the Toronto Stock Exchange

\footnotetext{
${ }^{6}$ For a complete list of the rules, see the European Parliament News release at http://www.europarl.europa.eu/news/en/news-room/content/20140411IPR43438/html/MEPs-vote-laws-to-regulatefinancial-markets-and-curb-high-frequency-trading.

${ }^{7}$ In this section, we provide a review of the international evidence on HFT, with a focus on European markets, given that our sample comes from the SSE. For a summary additional research on HFT that is not covered in footnote 1, see the review provided by the SEC at http://www.sec.gov/marketstructure/research/hft_lit_review_march_2014.pdf.
} 
to examine how a tax on HF traders impacts market quality. They find that quoted and effective spreads increase and revenues to liquidity supply decline, indicating that a reduction in HFT activity harms some dimensions of market quality. Jovanovic and Menkveld (2013) examine the entry of an HFT firm in the Dutch market and find a $15 \%$ decline in effective spreads and about $23 \%$ fall in adverse selection costs following the entry of this new HFT firm. Brogaard, Hendershott, Hunt, and Ysusi (2014) do not find any evidence of increased institutional trading costs as a result of increased HFT activity facilitated by technology upgrades on the London Stock Exchange. Brogaard, Hagströmer, Nordén, and Riordan (2015) study a colocation upgrade at NASDAQ OMX Stockholm which improves connectivity of high-speed traders. They find that liquidity increases for the overall market because high-frequency market makers use the enhanced speed to reduce their exposure to adverse selection and to better manage inventory.

In contrast to these positive findings are other studies that document negative effects of HFT. Examining trades by HFT firms routed via a single broker in the London and Tokyo equity markets, Bershova and Rakhlin (2013) find mixed evidence: While spreads fall with higher HFT activity, short-term volatility increases. The Australian Industry Super Network, an umbrella organization representing savings and retirement funds, commissioned a study that concludes "HFT activities cost non-HFT market participants, including long term investors, up to $\$ 1.9$ billion a year, with a best estimate of over $\$ 1.6$ billion a year." ${ }^{, 8}$ A study of foreign exchange markets conducted by the Bank of International Settlement finds that while HFTs can be beneficial to markets in normal times, they may be harmful to the functioning of markets in times of

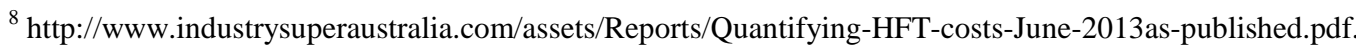


stress. ${ }^{9}$ In sum, whether HFT provides net benefits is still open for debate, which makes it challenging to devise appropriate rules to regulate these low latency traders.

\subsection{Short sale bans and market quality}

Researchers agree that short sellers perform a useful function by incorporating fundamental information into prices. Or, as Boehmer, Jones, and Zhang (2013) put it: "For the most part, financial economists consider short sellers to be the good guys." Karpoff and Lou (2010) find that short sellers detect financial fraud in firms about 19 months before the misrepresentation is publicly revealed. In a similar vein, Desai, Krishnamurthy, and Venkataraman (2006) show that short sellers pay attention to firms' accounting numbers and can anticipate earnings restatements several months in advance. Given the information-gathering role that short sellers perform, it is no surprise that market quality declines when regulatory bans are imposed on short selling.

The 2008 recession and the following European debt crisis in 2010-2011 saw several countries around the world impose ad hoc short sale bans to try to stem price declines. In the U.S., the SEC issued an emergency order restricting naked short selling in July 2008, and followed that up with an outright short selling ban in September. Analyzing the effects of this ban, Boehmer, Jones, and Zhang (2013) find that market quality worsens because many algorithmic traders cannot act as informal market makers. With less competition, formal market makers can now charge greater rents for liquidity provision. Battalio, Mehran, and Schultz (2012) study a similar decline is U.S. stock markets following the S\&P downgrade of the U.S. in 2011. They find that short sellers do not amplify stock price declines during times of market downturn.

\footnotetext{
${ }^{9}$ See full report at http://www.bis.org/publ/mktc05.pdf.
} 
The 2011 debt crisis saw the imposition of short sale bans in Greece, Turkey, Belgium, France, Italy, and Spain. Similar to the U.S. experience, the evidence points to dubious efficacy of short sale bans. Beber and Pagano (2013) study the effects of the 2008 stock price decline in 30 countries around the world. Comparing countries that did not impose a blanket ban on short-selling for all stocks to those that did, they conclude that the effect of such bans on stock prices is neutral at best. Bris, Goetzman, and Zhu (2007) analyze cross-sectional and time-series information from 46 countries and show that prices are more efficient in countries that allow and practice short sales.

\section{Institutional details of the Spanish Stock Exchange and time line of events}

The SSE has four trading platforms: Madrid, Barcelona, Bilbao, and Valencia. Trading is linked through the electronic Spanish Stock Market Interconnection System (SIBE), which handles more than $90 \%$ of transactions. The benchmark index is the IBEX-35, a capitalization-weighted index comprising the 35 most liquid Spanish stocks traded in the continuous market. ${ }^{10}$ Trading on SIBE is conducted from 9 a.m. to 5:30 p.m., with an opening call auction from 8:30 to 9:00 a.m. and a closing auction from 5:30 to 5:35 p.m. After the steep declines in markets Europe-wide during 2008, to which Spain was no exception, the IBEX-35 recovered remarkably to become Europe's best performer in 2009. However, 2010 was a down year due to increased country risk and the weakness of the European financial sector. The index fell $17.43 \%$ after fluctuating in a very wide range of $35 \%$ between its peak and low. The drop in share prices, however, did not erode the levels of activity. Indeed, 2010 set a new record in SSE trading volume.

\footnotetext{
10 The IBEX-35 index comprises the most important firms in the SSE. Perez-Rodriguez, Torra, and Andrada-Felix (2005) use the IBEX-35 sample for short horizon return forecasting. Meneu and Pardo (2004) use the IBEX-35 sample to examine large versus small investor behavior in the SSE.
} 
In response to the tailspin that the European markets witnessed in mid-2011, ESMA (a body that coordinates the European Union's market policies) issued a statement that all negative bets on financial stocks - in other words, short sales — would be curtailed in France, Belgium, Italy, and Spain effective August 11. This ban lasted until February 15, 2012, when the Spanish securities regulator, the Comision Nacional del Mercado de Valores (CNMV) announced that the prohibition on short sales of Spanish shares under the EU Short Selling Regulation (EU236/2012) was no longer in effect after February 15. However, as many market commentators had anticipated, once the ban was removed, prices declined precipitously, leading the CNMV to announce that "European shares have been hit with extreme volatility that might cause the disorderly functioning of financial markets." As a response, a second ban was introduced on July 23, 2012, which was subsequently lifted on January 31, 2013.

During this time the SSE also introduced major technology upgrades to integrate better with the bigger European exchanges and thereby attract HFT. Two major technology changes that facilitated faster trading were an upgrade of the SIBE-Smart platform and the introduction of colocation. Recognizing that HFT in securities markets was an established fact and a natural progression in the wake of the widespread introduction of electronic markets and the increasing use of computerized trading systems, the SSE committed to developing their trading infrastructure and communications technology. As part of their effort, they rolled out the SIBE-Smart platform on April 16, 2012, to better adapt SSE's systems to new demands in terms of transaction speed and volume in the market. Following up on this technological enhancement, the SSE began offering colocation capabilities at its Data Processing Center in Madrid on Nov. 12, 2012, enabling trading firms to install their own trading 
servers in close proximity to the exchange's trading engines and real-time price distribution systems. SSE officials stated that these efforts were expected to reduce latency, increase capacity for traders, and directly facilitate HFT. ${ }^{11}$

Below, we present a schematic timeline showing the dates and events described above:

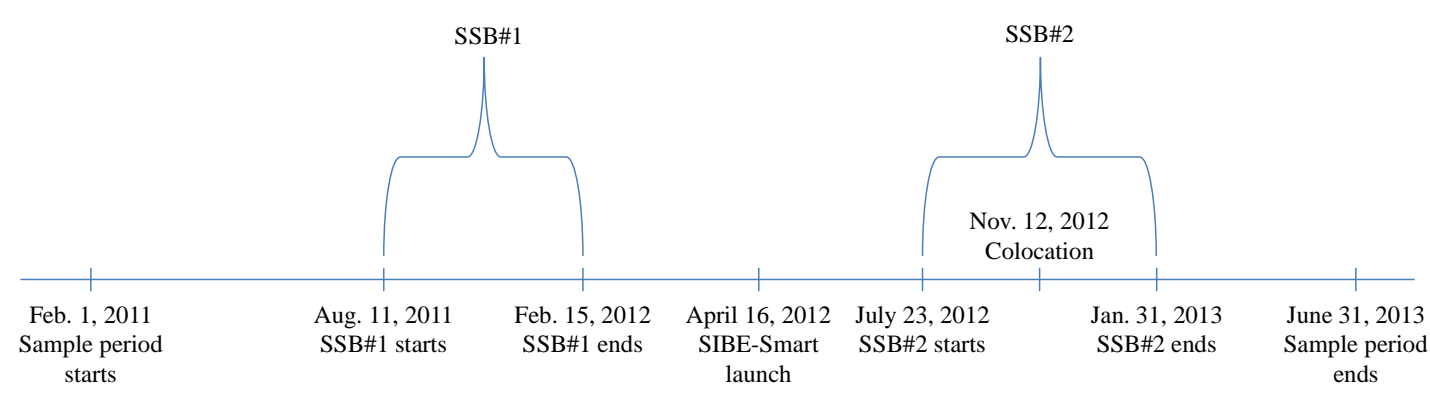

\section{Sample selection and market quality measures}

Our sample comprises the SSE-listed IBEX-35 constituents from January 2010 to December 2013. Due to index additions and deletions, our final sample includes 28 stocks that are index constituents throughout our sample period. We also separately examine the seven largest market capitalization (Blue Chip) stocks on the SSE, since previous studies document HF traders' preference for large and liquid stocks. ${ }^{12}$ For example, Hirschey (2013) finds that high frequency traders in his sample are more active in large than in small stocks (41\% vs. $15 \%)$.

Our data come from the SSE's trade files, which report all trades time-stamped up to the hundredth of a second before April 16, 2012 (launch of the SIBE-Smart) and milliseconds afterwards, and limit order book (LOB) files. For each trade, the record includes the price and size.

\footnotetext{
11 See announcement at http://www.world-exchanges.org/news-views/bme-successfully-upgradesspanish-stock-exchange\%E2\%80\%99s-trading-platform.

${ }^{12}$ We define the Blue Chip stocks as the seven IBEX-35 index constituents that were always in the top ten by market capitalization over the sample period.
} 
The order book files contain snapshots of the five best ask and bid quotes of the LOB taken each time the LOB changes as a result of trades, order submissions, cancelations, or modifications. For each LOB level we have the quote record, the number of orders at that quote, and the displayed depth. ${ }^{13}$ Relatively large buy (sell) trades are allowed to walk up (down) the book. Thus, the trade price is actually the marginal price, that is, the price at which the last share of the trade was transferred. In the SSE there are no round lot sizes; the minimum trade size is one share.

Both the trade and the LOB files contain a sequence code, allowing for a perfect match between trade and quotes. Since there are no price improvements (i.e., trades inside the spread) and every trade consumes liquidity either at the displayed ask or bid quote, it is straightforward to assign trade direction (i.e., buyer- or seller-initiated trades). A trade is classified as buyer-initiated (seller-initiated) if it consumes liquidity at the offer (demand) side of the LOB, which is commonly called the quote rule.

We filter out records from the opening, closing, and intraday short-lived call auctions in each file and use only quotes and trades from the continuous session. We also filter out prearranged trades.

\subsection{HFT activity measures}

Hendershott, Jones, and Menkveld (2011) compute message traffic in share volume and in dollar value as proxies for algorithmic trading. We compute the following four daily proxies for high-frequency trading: message traffic per minute ( $\left.\operatorname{MTMin}_{i d}\right)$, message traffic per euro-volume $\left(M T V €_{i d}\right)$, message traffic per volume in shares $\left(M T V S h_{i d}\right)$, and the number of non-zero quote-midpoint changes $\left(\Delta Q M i d_{i d}\right)$. We

\footnotetext{
${ }^{13}$ The SSE allows iceberg orders, but the quote files do not provide information on hidden volume (see Pardo and Pascual, 2012, for details).
} 
compute message traffic as the number of LOB updates per day, which is equivalent to summing all order submissions, cancelations, and revisions.

\subsection{Liquidity and market activity measures}

Boehmer, Fong, and Wu (2015) find that algorithmic trading intensity impacts market liquidity. We follow the literature and compute several liquidity and market activity metrics. In the formulas below, $i \in\{1, \ldots, 28\}, j \in\left\{1, \ldots, N_{i d}\right\}, k \in\{1, \ldots, 5\}$, $m \in\left\{1, \ldots, M_{d}\right\}$, and $t \in\left\{1, \ldots, T_{i d}\right\}$ are the sub-indexes for the $i$ stocks, $j$ LOB updates, $k$ steps in the LOB, $m$ 1-minute intervals, and $t$ trades, respectively. $N_{i d}$ and $T_{i d}$ are the number of LOB updates and trades in day $d$, respectively, and $M_{d}=510$ for a full-length ordinary session.

The quote midpoint $\left(q_{i j}\right)$ is the average between the best ask $\left(a_{i j}^{1}\right)$ and best bid ( $\left.b_{i j}^{1}\right)$ quotes of the LOB. Effective spread is two times the difference between the trade price $\left(p_{i t}\right)$ and $q_{i t}$, the prevailing quote midpoint before trade $t$, multiplied by the trade direction ( $x_{i t}=1$ for buyer initiated; $x_{i t}=-1$ for seller-initiated). In computing the daily measure, we weight each observation by trade size, to obtain the trade-weighted effective spread $\left(E S p r_{i d}\right)$ :

$$
E \operatorname{Spr}_{i d}=2 \frac{\sum_{t=1}^{T} s_{i t}\left(p_{i t}-q_{i t}\right) x_{i t}}{\sum_{t=1}^{T} s_{i t}}
$$

where $s_{i t}$ is the size (in shares) of the $t$-th trade.

The accumulated displayed LOB euro-depth $\left(\right.$ Depth $\left._{i j}\right)$ is 


$$
\operatorname{Depth}_{i j}=0.5\left(\sum_{k=1}^{5} v_{i j}^{a k} a_{i j}^{k}+\sum_{k=1}^{5} v_{i j}^{b k} b_{i j}^{k}\right)
$$

where $v_{i j}^{a k}\left(v_{i j}^{b k}\right)$ is the displayed depth (in shares) at the $k$-th ask (bid) level of the LOB for the $j$-th quote update. As in eq. [1], the average accumulated depth for stock $i$ and day $d\left(\right.$ Depth $\left._{i d}\right)$ is computed by weighting Depth $_{i j}$ by time.

Following Näes and Skjeltorp (2006), we compute the elasticity of the ask side of the LOB at the $j$-th update ( LOBElast ${ }_{i j}^{a}$ ) as

$$
\text { LOBElast }_{i j}^{a}=\frac{1}{5}\left[\frac{v_{i j}^{a 1}}{v_{i j}^{a 1} a_{i j}^{1} / q_{i j}-1}+\sum_{k=1}^{4} \frac{v_{i j}^{a(k+1)} / v_{i j}^{a k}-1}{a_{i j}^{k+1} / a_{i j}^{k}-1}\right] .
$$

The elasticity of the bid side of the LOB (LOBElast $t_{i j}^{b}$ ) is computed analogously. The LOB elasticity ( LOBElast $_{i j}$ ) is the average of LOBElast ${ }_{i j}^{a}$ and LOBElast LO $_{i j}^{b}$. We weight LOBElast $t_{i j}$ by time to obtain the corresponding daily summary measure ( LOBElast $_{i d}$ ). ESpr is an inverse measure of liquidity while Depth and LOBElast are direct measures of liquidity.

For market activity, we use the following three daily measures: Vol is the daily volume in shares; Trades is the daily number of trades, and Vol€ is the daily volume in euros, computed as

$$
\operatorname{Vol} €_{i d}=\sum_{t=1}^{T} s_{i t} p_{i t}
$$

\subsection{Volatility and price efficiency measures}

Our metric for daily stock price volatility is the realized volatility $\left(\right.$ RVolat $\left._{i d}\right)$, which is computed as the daily standard deviation of one-minute trade price returns, 


$$
\text { RVolat }_{i d}=\sqrt{\frac{1}{M_{d}} \sum_{m=1}^{M_{d}}\left(r_{i m}-\bar{r}_{i d}\right)^{2}}
$$

where $r_{i m}=\ln \left(p_{i m}\right)-\ln \left(p_{i m-1}\right)$, and $\bar{r}_{i d}=\frac{1}{M_{d}} \sum_{m=1}^{M_{d}} r_{i m}$.

We compute two daily proxies for price efficiency; the first-order autocorrelation of one-minute trade price returns $\left(\operatorname{Corr}_{i d}\right)$ and the pricing error standard deviation ( $\operatorname{PrErr}_{i d}$ ) estimated using Hasbrouck (1993). For each stock-day, we estimate a bivariate Vector Autoregressive (VAR) model for $\left\{r_{t}, x_{t}^{s}\right\}$, where $r_{t}$ is the return of trade $t$ and $x_{t}^{s}$ is the signed trade size. We choose the optimal VAR lag using the Akaike Information Criterion (AIC), and the model is estimated using Ordinary Least Squares regression. PrErr Pid $_{\text {in }}$ is obtained from the coefficients of the Vector Moving Average representation of the VAR model and the variance-covariance matrix of the residuals.

\subsection{Realized spread and price impact}

We estimate the revenue to liquidity providers using the realized spread $\left(R S p r_{i d}\right)$ and measure gross losses to liquidity demanders due to adverse selection using the price impact (PrImp) of a trade, as in Huang and Stoll (1996) and Hendershott, Jones, and Menkveld (2011). For stock $i$, the price impact of trade $t$ (PrImp $\left.{ }_{i t}\right)$ is two times the difference between the quote midpoint prevailing $\Delta$ seconds after the focal trade (i.e., $t+\Delta)$ and the midpoint prevailing right before trade $t$, multiplied by the trade direction:

$$
\operatorname{PrImp}_{i t}=2\left(q_{i t+\Delta}-q_{i t}\right) x_{i t} .
$$


The daily average $\operatorname{PrImp}_{i d}$ is weighted by trade size. The realized spread for trade $t$ is computed as

$$
R \operatorname{Spr}_{i t}=\mathrm{ESpr}_{i t}-\operatorname{PrImp}_{i t},
$$

and its daily average $\left(R S p r_{i d}\right)$ is weighted by trade size. Results are reported for $\Delta=5$ and 30 seconds.

\section{Results}

Table 1 presents the average descriptive statistics of our full sample as well as the Blue Chip stocks. Although the two samples have similar average stock prices, measures of HFT activity, liquidity, and volume are higher for the Blue Chip stocks than for the full sample. For example, while daily message traffic (which includes all updates to the limit order book) is about 46,397 for the full sample, it is more than twice that $(100,037)$ for the Blue Chip stocks. The Blue Chips also have higher volume and depth, and lower bid-ask spread, which is expected since they are the largest capitalization stocks in the SSE.

\section{[Table 1]}

To evaluate the impact on market quality, in all the remaining results reported in this section, we estimate an event's impact on our variable(s) of interest by running a pooled regression. The general form of the regression is as follows:

$$
Y_{i d}=\alpha+\beta_{E} E_{i d}+\beta_{V} \text { Volat }_{i d-1}+\varepsilon_{i d}
$$

where $Y_{i d}$ is each of the daily market quality metrics defined in Section 4 and $E_{i d}$ is a dummy for the event under consideration (SIBE-Smart introduction, colocation, or short sale bans). The coefficient of interest is $\beta_{E}$, the coefficient on the dummy that 
represents the post-event period. It captures the difference in each dependent variable between the pre- and post-event period. We use one-period-lagged IBEX-35 volatility (computed as the daily high/low) as a control variable $\left(\right.$ Volat $\left._{i d-1}\right)$ because Cáceres, Moreno, and Rodriguez (2014) show that the short sale bans on the SSE affect volatility. We also report the estimated percentage change in each dependent variable,

computed as $100\left[\beta_{E} /\left(\alpha+\beta_{V} \overline{\text { Volat }}\right)\right]$. Standard errors are clustered by both stock and date using the procedure outlined in Thompson (2011).

In Section 5.1 we present the overall effects from before the first change is introduced to after all of the changes are completed, to determine the net effect of the bans and the technology upgrades on market quality. In the subsequent subsections we present the effects of each individual event.

\subsection{Effects of all events combined}

We begin by examining changes in HFT activity in the SSE before and after the time window that includes the technology changes and short sale bans. The pre-events period is Feb 1, 2011 to Jun 31, 2011 and the post-events period is Feb 1, 2013 to Jun 31, 2013. We report four proxies for HFT: message traffic per minute (MTMin), message traffic per euro volume (MTV€), message traffic per share volume (MTVSh), and the number of non-zero quote midpoint changes $(\triangle Q M i d)$. Results are in Table 2 Panel A.

[Table 2]

For the full sample, there is a weak (significant at 10\%) increase in message traffic per minute. None of the other proxies for HFT show any significant change between the pre- and post-periods. Even for the Blue Chip stocks, which are the most 
liquid and are expected to attract the most HFT attention (Hirschey, 2013), we find significant change in message traffic per minute and message traffic per euro volume, while the other two proxies (message traffic per share volume and the number of nonzero quote midpoint changes) show no change. Overall, there is only weak evidence that during our event window there is any significant boost to HFT activity on the SSE.

To examine changes in stock liquidity and market activity, we examine liquidity and trading activity metrics that earlier research has linked to HFT. In Table 2, Panels B and $\mathrm{C}$, we report the estimated coefficients from the pooled regression model. The dependent variables that capture liquidity are the trade weighted effective spread (ESpr), quoted depth (Depth), and limit order book elasticity (LOBElast), reported in Panel B, and the market activity variables in Panel $\mathrm{C}$ are daily volume in shares ( $\mathrm{Ool})$, daily volume in euros (Vol€), and daily number of trades (Trades).

By all measures, liquidity declines. For the full sample as well as the Blue Chip stocks, the trade-weighted effective spread increases and limit order book elasticity decreases. There is no offsetting increase in depth; in fact, depth shows no significant change in this period. The market activity measures show similar patterns: Most measures show a significant decline. Overall, the results are consistent with liquidity reduction in the SSE stocks during this period.

Brogaard, Hendershott, and Riordan (2014a) find that HFT helps incorporate information faster into prices and make them more efficient, while Jiang, Peterson, and Doran (2014) find that binding short sale constraints contribute to volatility. Furthermore, in order-driven markets (like the SSE), Menkveld (2013) finds that some HFTs may take on a market-making role, while Kirilenko, Kyle, Samadi, and Tuzun (2014) find that during the U.S. Flash Crash in 2010, HFTs consumed liquidity through 
aggressive (liquidity demanding) orders and exacerbated the price declines. Based on the previous research, we next examine changes in price efficiency and volatility (Table 3 Panel A) and realized spread and price impact of trades (Table 3 Panel B).

\section{[Table 3]}

In Panel A, for the full sample, pricing error (PrErr) and volatility (RVolat) show little change; however, return autocorrelations (Corr) increase significantly, indicating that prices become less efficient. For the Blue Chip stocks, there is weak evidence of a reduction PrErr. There are no changes in other efficiency or volatility metrics. Overall, there is little evidence that the SSE stocks saw any appreciable increase in price efficiency during this period.

In Panel B, we report the realized spread (RSpr) and price impact (PrImp) measures for five and 30 seconds after each trade. For the full sample, there is no change in realized spread, indicating that there is no significant change in the revenue earned by liquidity providers. Price impact increases at all horizons. Recalling the increase in autocorrelation of trade price returns (Corr) from Table 3, Panel A, the increase in price impact reported here is consistent with order flow autocorrelation increasing during this period. The results for the Blue Chip stocks show similar increase in price impacts, but unlike the full sample, for these liquid stocks, realized spreads fall significantly. So liquidity providers' revenues from making a market in the Spanish Blue Chips fall in the post-events period. One explanation consistent with our results is that the changes may have attracted HFTs that follow arbitrage or speculative strategies (make directional bets) rather than market-making strategies (Menkveld and Zoican, 2015). 


\subsection{Effects of the introduction of SIBE-Smart}

SIBE-Smart was introduced on April 16, 2012 to seamlessly connect the SSE with the other exchanges in Europe and facilitate high-speed traders. To evaluate the impact of this technological upgrade and the resulting faster trading platform, we compute and test for differences in the measures of various dimensions of market quality by comparing the pre-SIBE-Smart (March 1, 2012 - April 15, 2012) and postSIBE-Smart (April 16, 2012 - May 31, 2012) periods. In Table 4, we present the changes in HFT activity (Panel A), liquidity (Panel B), and market activity (Panel C) measures in this period.

\section{[Table 4]}

Regarding HFT activity, for the full sample all of the proxies of high speed trading except message traffic per volume show an increase post-SIBE-Smart introduction. Traffic per minute, volume (in euro) and number of quote mid-point changes all increase. For the Blue Chip stocks, two of the four metrics (message traffic per minute and quote mid-point changes) show significant increases as well. Overall, the evidence suggests that the smart trading platform indeed succeeded in attracting the high speed traders.

We next examine changes in stock liquidity and market activity following the SIBE-Smart introduction and report results in Table 4, Panel B. By most measures, liquidity declines. For the full sample, the trade-weighted effective spread increases while limit order book depth and elasticity decrease. For the measures of market activity in Table 4, Panel C, euro-volume and trade size show significant declines. Results for the Blue Chip stocks are similar. Overall, the results are consistent with liquidity 
reduction in the SSE stocks during this period in spite of the introduction of the smart platform, which attracts some high speed traders.

SIBE-Smart may facilitate high speed traders, but their activities do not seem to improve liquidity on the SSE. So we next ask if there are any other benefits to this upgrade in terms of improvements in price efficiency and/or reduction in volatility. Results are reported in Table 5, Panel A.

\section{[Table 5]}

For the full sample as well as the Blue Chip stocks there are significant increases in realized volatility, return autocorrelation, and standard deviation of pricing errors. We do not find any evidence that the introduction of the SIBE-Smart platform helps improve the informativeness of prices by reducing pricing errors. Thus, our results are different from Riordan and Storkenmaier (2012), who analyze a technology upgrade on the Deutsche Boerse and find liquidity improvements due to a reduction in adverse selection. They also find that prices become more efficient after the upgrade. In contrast, and similar to our findings, Menkveld and Zoican (2015) find that for a NASDAQ-OMX speed upgrade, spreads increase, possibly due to increased speculative trading by high frequency "bandits" who increase adverse selection costs. It appears that in our setting, the effect of regulatory uncertainties (the impending first short sale ban) countervail the positive effects of technology upgrades that accrue during normal times.

We also examine the effect of this technological upgrade on the realized spreads and price impacts of trades. As before, we report the regression coefficients with realized spreads and price impacts calculated at two time horizons: 5 and 30 seconds. Results are reported in Table 5, Panel B. For the full sample as well as the Blue Chip 
stocks, there is no change in realized spread, indicating that there is no significant change in the revenue earned by liquidity providers. Price impact increases at all horizons, evidencing higher adverse selection.

\subsection{Effects of the two short sale bans}

The SSE bans short selling twice during our sample period. The first short sale ban begins on August 11, 2011 and is lifted on February 15, 2012, and it affects 16 stocks from the financial sector. There are no technological changes introduced during this ban. The second short sale ban begins on July 23, 2012, and ends on January 31, 2013, affecting all the SIBE-listed stocks. However, while this second ban is in effect, the SSE introduces colocation on November 12, 2012. To control for this potentially relevant event, we limit the post-event period for the second short sale ban from July 23, 2012 to November 11, 2012. As in previous tests, we use a pooled regression model with the (Volat -1 ) control variable, and a dummy for the second short sale ban (SSB2), to indicate the incremental difference in each variable of interest during the second short sale ban, compared to the first short sale ban. We begin by examining the changes in HFT activity, liquidity, and market activity during the second ban, compared to the first ban. Results are presented in Table 6 .

\section{[Table 6]}

For the full sample as well as the Blue Chip stocks, most metrics of HFT activity (Panel A) show a reduction, indicating that relative to the first ban, there is additional decline in HFT during the second ban. For example, compared to the first ban, the second ban saw 75.89 fewer messages per minute, which is significant at the $1 \%$ level. In Panel B, all liquidity measures show significant reductions during the second ban relative to their levels during the first ban. This is true of the full sample as well as the 
Blue Chip stocks. Market activity (Panel C) shows across-the-board reductions for all the Blue Chip stocks.

Reflecting the findings in the previous sections, when examining the price efficiency and volatility impacts of the second ban, in Table 7, Panel A, we find that return autocorrelations increase and volatility shows no change.

\section{[Table 7]}

Realized spread and price impact estimates in Table 7, Panel B, also show the same patterns as before: increased realized spreads and price impacts at both time horizons during the second short sale ban, relative to the first ban.

\subsection{Effects of the introduction of colocation}

Colocation reduces latency for high-speed traders, and prior research shows that this leads to improved market outcomes. For example, Conrad, Wahal, and Xiang (2015) study a technological change on the Tokyo Stock Exchange that reduces latency by allowing colocation and find that after the upgrade, price efficiency increases and trading cost declines.

To facilitate high-speed traders, the SSE introduced colocation services on November 12, 2012. The peculiar nature of this introduction of colocation was that it happened during a time when the Spanish stock market had a regulatory short sale ban in effect: The second short sale ban began on July 23, 2012 and ended on January 31, 2013. In this section, we test for differences in various metrics of market quality before and after colocation. First, we compare the "pre-colocation" period (July 23, 2013 November 11, 2012), a time with banned short-selling and no colocation, with the "post-colocation" period (November 12, 2012 - January 31, 2013), a time with banned 
short-selling and colocation. This test isolates the effect of colocation during a short sale ban. Second, we compare the "pre-ban" period (April 16, 2012 - July 22, 2012), a time with no ban and no colocation, with the "post-ban" period (February 1, 2013 - June 31, 2013), a time with no ban but with colocation. This test isolates the effect of colocation without a short sale ban. These two tests together provide a complete picture of how colocation affects the SSE stocks under a regime of short sale ban versus no short sale ban. Table 8 presents the results.

\section{[Table 8]}

The Post- vs. pre-colocation dummy, which captures the effect of colocation in the presence of a short sale ban, shows declines in three of the four HFT proxies (Panel A). This is expected, since regulatory impediments lead to a decline in HFT activity (Boehmer, Jones, and Zhang, 2013). Somewhat unexpectedly, we find similar reductions in HFT activity when comparing the effect of colocation without the ban (see the variable Post- vs. pre-ban). The reductions are not significant in most of the Blue Chip stocks, but overall, our results robustly document that colocation does not lead to any increase in HFT, with or without the short sale ban.

The liquidity and market activity impacts of colocation show some variation across the two event windows. In Table 8, Panels $\mathrm{B}$ and $\mathrm{C}$, we present the results of the effects of colocation, with and without ban, on liquidity and market activity. While we find an across-the-board decline in liquidity and market activity measures when comparing the periods before and after colocation with the short sale ban (see variable Post- vs. pre-colocation), we find that effective spreads decline and depth and order book elasticity increase significantly when comparing the effects of colocation without the ban (see variable Post- vs. pre-ban). This is consistent with the literature, which 
documents that increased HFT facilitated by colocation improves market liquidity characteristics. The richness of our unique setting allows us to show that such improvements do not accrue if there are regulatory restrictions to trading.

In Table 9, we show that colocation is accompanied by volatility reduction but no significant change in realized spread, both with and without the ban.

\section{[Table 9]}

\section{Robustness checks}

In robustness checks, we have tested the pre- versus post-ban time window for market quality effects of the first and the second short sale bans separately (instead of the incremental test of the second ban relative to the first, as presented in the main tables). Similar tests for liquidity and market activity metrics confirm the results presented: Both bans show liquidity reduction but the second ban shows stronger declines. Price efficiency metrics and realized spreads estimated separately around each

of the two bans show results consistent with those presented. We also use additional proxies for liquidity, for example the Amihud illiquidity measure and relative bid-ask spread, and compute realized spread and price impact of trades at other time horizons (15 seconds). All conclusions hold.

\section{Conclusions}

Existing studies show that high-frequency traders, who largely dominate modern markets, improve liquidity and price efficiency but may also adversely select other investors and try to game other traders by creating congestion in the trading platforms. Our investigation of how HFT impacts markets reveals the key role of regulation in this equation: Whether HFTs have a positive or negative effect depends critically on the 
regulatory framework within which these fast traders operate. In this study we identify a unique timeline of events that allow us to shed light on how market quality is affected when regulatory restrictions are juxtaposed with technological inducements to facilitate HFT.

During 2011 and 2012, the SSE introduced two major technological changes to attract and facilitate HFT. In April of 2012 the SSE introduced the SIBE-Smart, a technologically upgraded trading platform, followed by colocation facilities in November of 2012. During this time, there were two short sale bans imposed by the SSE. The first ban ended just before the SIBE-Smart introduction and the second ban started before the colocation event and ended several months later. We use this juxtaposition of events to reveal how HFT activity, market liquidity, price efficiency, returns to liquidity provision, and adverse selection are affected.

We document several findings. First, overall there is no increase in HFT when comparing the periods before and after all these events. By most metrics, liquidity worsened and price efficiency fell. Although the SIBE-Smart introduction preceded the first ban and managed to attract a modest increase in HFT, it was accompanied by reductions in liquidity and price efficiency. In contrast, the colocation event was introduced during the second short sale ban and failed to boost HFT activity in any significant way, also leading to a worsening of market quality. Finally, our timeline also allows us to isolate the effects of colocation with and without a short-sale ban. In comparing the effects of colocation with and without a ban, we find that although HFT does not increase in either case, liquidity improves with colocation in the absence of a ban but declines rather steeply when the ban is in effect. 
When regulatory restrictions are present, as in our setting, we find none of the positive effects of HFT-friendly technological improvements that have been documented by previous studies. Our results indicate that the effects of regulatory restrictions create serious impediments that technological inducements may not be capable of overcoming. Given that the bulk of the findings in HFT and short sale literature come from the U.S. markets, our study also adds to the small but growing body of evidence from an international markets perspective. 


\section{References}

Baron, Matthew, Jonathan Brogaard, and Andrei Kirilenko, 2012, The trading profits of high-frequency traders, Working paper.

Battalio, Robert H., Hamid Mehran, and Paul H. Schultz, 2012, Market declines: What is accomplished by banning short-selling? Current Issues in Economics and Finance $18(5)$.

Beber, Alessandro, and Marco Pagano, 2013, Short-selling bans around the world: Evidence from the 2007-2009 crisis, Journal of Finance 61(8): 343-381

Bershova, Nataliya, and Dmitry Rakhlin, 2013, High-frequency trading and long-term investors: A view from the buy-side, Journal of Investment Strategies 2(2): 25-69.

Blas, Cecilio Gil, Javier González, , and Victoria Villanueva,. 2011, Desarrollos recientes de la microestructura de los mercados secundarios de acciones. CNMV Working Paper \#50.

Boehmer, Ekkehart, Kingsley Fong, and Juan (Julie) Wu, 2015, International evidence on algorithmic trading, Working paper.

Boehmer, Ekkehart, Charles M. Jones, and Xiaoyan Zhang, 2013, Shackling short sellers: The 2008 shorting ban, Review of Financial Studies 26(6): 1363-1400.

Bris, Arturo, William Goetzmann, and Ning Zhu, 2007, Efficiency and the bear: Short sales and markets around the world, Journal of Finance 62(3): 1029-1079.

Brogaard, Jonathan, 2010, High frequency trading and price volatility, Working paper.

Brogaard, Jonathan, Björn Hagströmer , Lars L. Nordén, and Ryan Riordan, 2015, Trading fast and slow: colocation and liquidity, Review of Financial Studies, forthcoming.

Brogaard, Jonathan, Terrence Hendershott, and Ryan Riordan, 2014a, High frequency trading and price discovery, Review of Financial Studies 27: 2267-2306.

Brogaard, Jonathan, Terrence Hendershott, and Ryan Riordan, 2014b, High frequency trading and the 2008 short sale ban, Working paper.

Brogaard, Jonathan, Terrence Hendershott, Stefan Hunt, and Carla Ysusi, 2014, High frequency trading and the execution costs of institutional investors, The Financial Review 49: 345-369.

Cáceres, Esther, David Moreno, and Rosa Rodriguez, 2014, A study on short-selling constraints: total ban versus partial ban, Applied Economics Letters, 22(2): 99-103.

Conrad, Jennifer, Sunil Wahal, and Jin Xiang, 2015, High-frequency quoting, trading, and the efficiency of prices, Journal of Financial Economics, 116: 271-291.

Desai, Hemang, Srinivasan Krishnamurthy, and Kumar Venkataraman, 2006, Do short sellers target firms with poor earnings quality? Evidence from earnings restatements, Review of Accounting Studies 11(1): 71-90. 
Egginton, Jared F., Bonnie F. Van Ness, and Robert A. Van Ness, 2014, Quote stuffing, Working paper.

ESMA, 2014, High frequency trading activity in EU equity markets. Economic Report $\# 1$.

Hasbrouck, Joel, 1993, Assessing the quality of a security market: A new approach to transaction-cost measurement, Review of Financial Studies 6(1): 191-212.

Hasbrouck, Joel, and Gideon Saar, 2013, Low-latency trading, Journal of Financial Markets 16: 646-679.

Hendershott, Terrence, Charles M. Jones, and Albert J. Menkveld, 2011, Does algorithmic trading improve liquidity? Journal of Finance 66: 1-33.

Hirschey, Nicholas, 2013, Do HFTs anticipate buying and selling pressures? Working Paper.

Huang and Stoll, 1996, Dealer vs auction markets: A paired comparison of execution costs on NASDAQ and the NYSE, Journal of Financial Economics 41: 313-357.

Jiang, Danling, David R. Peterson, and James S. Doran, 2014. Short-sale constraints and the idiosyncratic volatility puzzle: An event study approach, Journal of Empirical Finance 28: 36-59.

Jovanovic, Boyan, and Albert J. Menkveld, 2013, Middlemen in limit order markets, Working paper.

Karpoff, Jonathan M., and Xiaoxia Lou, 2010, Short sellers and financial misconduct, Journal of Finance 65(5): 1879-1913.

Kirilenko, Andrei, Albert S. Kyle, Mehrdad Samadi, and Tugkan Tuzun, 2014, The flash crash: The impact of high-frequency trading on an electronic market, Working paper.

Korajczyk, Robert A., and Dermot Murphy, 2015, High frequency market making to large institutional trades, Working paper.

Malinova, Katya, Andreas Park, and Ryan Riordan, 2014, Do retail traders suffer from high frequency traders? Working paper.

Meneu, Vicente, and Angel Pardo, 2004, Pre-holiday effect, large trades and small investor behavior, Journal of Empirical Finance 11(2): 231-246.

Menkveld, Albert J., 2013, High frequency trading and the new market makers, Journal of Financial Markets, 16: 712-740.

Menkveld, Albert J., and Marius A. Zoican, 2015, Need for speed? Exchange latency and liquidity, Working Paper.

Näes, Randi, and Johannes A. Skjeltorp, 2006, Order book characteristics and the volume-volatility relation: Empirical evidence from a limit order market, Journal of Financial Market 9(4): 408-432. 
Pardo, Ángel, and Roberto Pascual, 2012, On the hidden side of liquidity, European Journal of Finance 18(10): 949-967.

Perez-Rodriguez, Jorge, Salvador Torra, and Julian Andrada-Felix, 2005, STAR and ANN models: Forecasting performance on the Spanish "Ibex-35" stock index, Journal of Empirical Finance 12: 490-509.

Riordan, Ryan, and Andreas Storkenmaier, 2012, Latency, liquidity, and price discovery, Journal of Financial Markets, 15: 416-437.

Thompson, Samuel B., 2011, Simple formulas for standard errors that cluster by both firms and time, Journal of Financial Economics, 99: 1-10.

van Kervel, Vincent, and Albert J. Menkveld, 2015, High-frequency trading around large institutional orders, Working paper. 


\section{TABLE 1}

\section{Sample Statistics}

We provide average daily statistics for our full sample of 28 stocks and the subset of seven Blue Chip stocks for the period January 2010 to December 2013. We provide statistics on market capitalization; transaction price; volume in shares and euros; number of trades; relative bid-ask spreads; displayed depth at the five best levels of the LOB, both in shares and euros; the absolute open-to-close returns; the ratio between the highest and the lowest trade price, and message traffic. Standard deviations are in parentheses. We use the rank-sum statistic of Wilcoxon to tests for equality of medians. ***, **, and * indicate statistically significantly differences at the $1 \%, 5 \%$, and $10 \%$ level, respectively.

\begin{tabular}{lrc} 
& All stocks & Blue Chips \\
\hline Market Cap. (/10000) & 1151334.09 & $3559233.79 * * *$ \\
& $(1721046.88)$ & $(2049702.52)$ \\
Price & 17.09 & 19.94 \\
& $(16.82)$ & $(24.55)$ \\
Volume (/10000) & 551.43 & $1561.38 * *$ \\
& $(972.30)$ & $(1507.33)$ \\
Euro Volume (/10000) & 4421.48 & $14026.56 * * *$ \\
& $(7476.87)$ & $(10346.16)$ \\
Trades & 2786.76 & $6650.74 * * *$ \\
& $(2962.78)$ & $(3950.21)$ \\
Relative bid-ask spread & 0.0016 & $0.0008 * * *$ \\
& $(0.0006)$ & $(0.0003)$ \\
Depth & 58181.41 & 74376.74 \\
& $(91080.94)$ & $(50423.75)$ \\
Depth (€) & 385433.38 & $792616.64 * * *$ \\
Abs. open-to-close returns & $(353945.77)$ & $(507494.22)$ \\
Message Traffic & 0.0142 & 0.0128 \\
& $(0.0032)$ & $(0.0023)$ \\
& 0.0297 & 0.0268 \\
& $(0.0061)$ & $(0.0043)$ \\
& 46396.96 & $100037.46 * * *$ \\
& $(43541.41)$ & $(57042.96)$ \\
& & \\
& & \\
& &
\end{tabular}




\section{TABLE 2}

\section{All events combined: HFT, liquidity, and market activity}

We evaluate the net impact of the technological upgrades and short sale bans on the SSE from 2011 to 2012 on HFT activity (Panel A), liquidity (Panel B), and market activity (Panel C). We compare the "pre-events" (February 1, 2011 - June 31, 2011) and "post-events" periods (February 1, 2013 - June 31, 2013). This table presents the estimated coefficients from pooled regressions with double-clustered standard errors. HFT proxies are: message traffic per minute (MTMin); message traffic per euro-volume $(M T V €)$; message traffic per volume in shares (MTVSh), and the number of non-zero quote midpoint changes $(\triangle Q M i d)$. Liquidity proxies are: effective spread weighted by trade size (x100) (ESpr); time-weighted quoted depth (Depth); and LOB elasticity (LOBElast). ESpr is an inverse measure while Depth and LOBElast are direct measures of liquidity. Market activity proxies are: the daily volume in shares $(\mathrm{Vol})\left(/ 10^{4}\right)$; the daily volume in euros $\left(\right.$ Vol€) $\left(/ 10^{6}\right)$, and the daily number of trades $($ Trades). The explanatory variable of interest is the dummy for the post-events period ("Post-Events"). We use the one period lagged IBEX-35 volatility variable (Volat.l) as a control. We report results for our full sample of 28 stocks (All Stocks) and for the Blue Chips separately. We also report the implied estimated percentage change in each proxy (\% change).

\section{Panel A: HFT}

\begin{tabular}{|c|c|c|c|c|c|c|c|c|}
\hline & \multicolumn{4}{|c|}{ All stocks } & \multicolumn{4}{|c|}{ Blue chips } \\
\hline Variable & MTMin & $M T V €$ & MTVSh & $\triangle Q M i d$ & MTMin & $M T V €$ & MTVSh & $\triangle Q M i d$ \\
\hline Cons. & $64.36 * * *$ & $0.2001 * * *$ & $0.0411 * * *$ & $4536.12 * * *$ & $116.23 * * *$ & $0.0605 * * *$ & $0.0139 * *$ & $5818.00 * * *$ \\
\hline Post-Events & $19.16 *$ & 0.0941 & 0.0070 & -622.46 & $76.16 * * *$ & $0.0811 * * *$ & 0.0175 & 1135.07 \\
\hline Volat_-1 & $8.93 * * *$ & 0.0054 & 0.0002 & $864.05 * * *$ & $21.48 * * *$ & 0.0018 & -0.0004 & $1648.27 * * *$ \\
\hline Obs. & 5852 & 5852 & 5852 & 5852 & 1463 & 1463 & 1463 & 1463 \\
\hline Adj.-R2 & 0.0149 & 0.0144 & 0.0029 & 0.0144 & 0.1046 & 0.3454 & 0.0562 & 0.0375 \\
\hline $\mathrm{F}$ & 138.41 & 68.43 & 23.09 & 95.15 & 231.03 & 614.89 & 91.12 & 73.54 \\
\hline$\%$ change $^{\dagger}$ & $30 \% *$ & $47 \%$ & $17 \%$ & $-14 \%$ & $65 \% * * *$ & $134 \% * * *$ & $126 \%$ & $19 \%$ \\
\hline
\end{tabular}

$* * *, * *, *$ indicates statistically significant at the $1 \%, 5 \%$ and $10 \%$ level, respectively.

$\dagger$ Control variable evaluated at the mean 
TABLE 2 (Cont.)

All events combined: HFT, liquidity, and market activity

Panel B: Liquidity

\begin{tabular}{|c|c|c|c|c|c|c|}
\hline Variable & ESpr & Depth & LOBElast & ESpr & Depth & LOBElast \\
\hline Cons. & $0.0870 * * *$ & $236000 * * *$ & $26800 * * *$ & $0.0503 * * *$ & $476000 * *$ & $45900 * * *$ \\
\hline Post-Events & $0.0234 * * *$ & -4250 & $-3790 * * *$ & $0.0099 * * *$ & -63300 & $-6570 * * *$ \\
\hline Volat-1 & $0.0064 * * *$ & $-17900 * * *$ & $-1340 * * *$ & $0.0027 * * *$ & $-33500 * *$ & $-2360 * * *$ \\
\hline Obs. & 5852 & 5852 & 5852 & 1463 & 1463 & 1463 \\
\hline Adj.-R2 & 0.0443 & 0.002 & 0.0307 & 0.0708 & 0.0157 & 0.0684 \\
\hline $\mathrm{F}$ & 316.66 & 14.53 & 579.02 & 103.45 & 33.30 & 238.72 \\
\hline$\%$ change $^{\dagger}$ & $27 \% * * *$ & $-2 \%$ & $-14 \% * * *$ & $20 \% * * *$ & $-13 \%$ & $-14 \% * * *$ \\
\hline \multicolumn{7}{|c|}{ Panel C: Market activity } \\
\hline Variable & Vol & Vol€ & Trades & Vol & Vol€ & Trades \\
\hline Cons. & $451.28 * * *$ & $48.80 * * *$ & $2555.38 * * *$ & $1390.53 * * *$ & $155.65 * * *$ & $6144.32 * * *$ \\
\hline Post-Events & 112.76 & $-21.23 * *$ & $-361.91 * * *$ & $-300.76 * * *$ & $-75.55 * * *$ & $-1190.00 * * *$ \\
\hline VLT(-1) & $51.39 * * *$ & $3.54 * * *$ & $230.39 * * *$ & $152.46 * * *$ & $11.95 * * *$ & $652.77 * * *$ \\
\hline Obs. & 5852 & 5852 & 5852 & 1463 & 1463 & 1463 \\
\hline Adj.-R2 & 0.0033 & 0.0158 & 0.0044 & 0.0114 & 0.0902 & 0.0223 \\
\hline $\mathrm{F}$ & 29.39 & 206.25 & 77.08 & 35.41 & 200.31 & 59.24 \\
\hline$\%$ change $^{\dagger}$ & $25 \%$ & $-43 \% * *$ & $-14 \% * * *$ & $-22 \% * * *$ & $-48 \% * * *$ & $-19 \% * * *$ \\
\hline
\end{tabular}

$* * *, * *, *$ indicates statistically significant at the $1 \%, 5 \%$ and $10 \%$ level, respectively.

$\dagger$ Control variable evaluated at the mean 


\section{TABLE 3}

\section{All events combined: volatility, price efficiency, realized spreads, and price impacts}

We evaluate the net impact of the technological upgrades and short sale bans on the SSE from 2011 to 2012 on volatility and price efficiency (Panel A), and realized spreads and price impacts (Panel B). We compare the "pre-events" (February 1, 2011 - June 31, 2011) and "post-events" periods (February 1, 2013 - June 31, 2013). This table presents the estimated coefficients from pooled regressions with double-clustered standard errors. In Panel A, realized volatility (RVolat) is the daily standard deviation of 1minute trade price returns (x100). Efficiency proxies are the autocorrelation of 1-minute trade price returns (Corr) and the pricing error standard deviation (PrErr), estimated using Hasbrouck (1993). In Panel B, price impact (PrImp) measures the informativeness of trades (adverse selection cost), and the realized spread (RSpr) measures how much of the effective spread is earned by the liquidity provider. Price impact and realized spread are measured over 5-second and 30-second horizons after the trade. The explanatory variable of interest is the dummy for the post-events period ("Post-Events"). We use the one period lagged IBEX-35 volatility variable (Volat.- ) as a control. We report results for our full sample of 28 stocks (All Stocks) and for the Blue Chips separately. We also report the implied estimated percentage change in each proxy (\% change).

Panel A: Realized volatility and price efficiency

\begin{tabular}{|c|c|c|c|c|c|c|}
\hline \multirow[b]{2}{*}{ Variable } & \multicolumn{3}{|c|}{ All stocks } & \multicolumn{3}{|c|}{ Blue chips } \\
\hline & RVolat & Corr & PrErr & RVolat & Corr & PrErr \\
\hline Cons. & $0.0756 * * *$ & $0.0619 * * *$ & $0.0214 * * *$ & $0.0610 * * *$ & $0.0636 * * *$ & $0.0121 * * *$ \\
\hline Post-Events & 0.0045 & $0.0082 * * *$ & 0.0001 & 0.0044 & 0.0055 & $-0.0012 * *$ \\
\hline Volat $_{1}$ & $0.0097 * * *$ & 0.0020 & $0.0016 * * *$ & $0.0089 * * *$ & -0.0004 & $0.0007 * * *$ \\
\hline Obs. & 5852 & 5852 & 5852 & 1463 & 1463 & 1463 \\
\hline Adj.-R2 & 0.0521 & 0.0074 & 0.0051 & 0.1323 & 0.0031 & 0.0193 \\
\hline $\mathrm{F}$ & 291.93 & 22.60 & 34.06 & 138.90 & 2.25 & 20.79 \\
\hline$\%$ change $^{\dagger}$ & $6 \%$ & $13 \%$ & $0 \%$ & $7 \%$ & $9 \%$ & $-10 \% * *$ \\
\hline
\end{tabular}

***,**,* indicates statistically significant at the $1 \%, 5 \%$ and $10 \%$ level, respectively.

$\dagger$ Control variable evaluated at the mean 
TABLE 3 (Cont.)

All events combined: volatility, price efficiency, realized spreads and price impacts

Panel B: Realized spread and price impact

\begin{tabular}{|c|c|c|c|c|c|c|c|c|}
\hline Variable & RSpr5 & RSpr30 & PrImp5 & PrImp30 & RSpr5 & RSpr30 & PrImp5 & PrImp30 \\
\hline Cons. & $0.0350 * * *$ & $0.0264 * * *$ & $0.0398 * * *$ & $0.0485 * * *$ & $0.0194 * * *$ & $0.0138 * * *$ & $0.0243 * * *$ & $0.0299 * * *$ \\
\hline Post-Events & -0.0037 & -0.0062 & $0.0178 * * *$ & $0.0203 * * *$ & $-0.0078 * * *$ & $-0.0077 * * *$ & $0.0123 * * *$ & $0.0122 * * *$ \\
\hline Volat $_{-1}$ & 0.0003 & $-0.0014 *$ & $0.0055 * * *$ & $0.0071 * * *$ & -0.0005 & $-0.0010 *$ & $0.0035 * * *$ & $0.0040 * * *$ \\
\hline Obs. & 5852 & 5852 & 5852 & 5852 & 1463 & 1463 & 1463 & 1463 \\
\hline Adj.-R2 & 0.004 & 0.014 & 0.1342 & 0.1189 & 0.1276 & 0.1297 & 0.2688 & 0.1928 \\
\hline $\mathrm{F}$ & 25.1373 & 67.1262 & 939.5477 & 798.7403 & 170.67 & 134.46 & 466.40 & 323.45 \\
\hline$\%$ change $^{\dagger}$ & $-11 \%$ & $-24 \%$ & $45 \% * * *$ & $42 \% * * *$ & $-40 \% * * *$ & $-56 \% * * *$ & $50 \%$ *** & $41 \% * * *$ \\
\hline
\end{tabular}

$* * *, * * *$ indicates statistically significant at the $1 \%, 5 \%$ and $10 \%$ level, respectively.

$\dagger$ Control variable evaluated at the mean 


\section{TABLE 4}

\section{SIBE-Smart: HFT, liquidity, and market activity}

We evaluate the impact of the introduction of the SIBE Smart on HFT activity (Panel A), liquidity (Panel B), and market activity (Panel C). We compare the "pre-Smart" (March 1, 2012 - April 15, 2012) and "post-Smart" periods (April 16, 2012 - May 31, 2012). This table presents the estimated coefficients from pooled regressions with double-clustered standard errors. HFT proxies are: message traffic per minute (MTMin); message traffic per euro-volume (MTV€); message traffic per volume in shares (MTVSh), and the number of non-zero quote midpoint changes ( $\triangle Q M i d)$. Liquidity proxies are: effective spread weighted by trade size (x100) (ESpr); time-weighted quoted depth (Depth); and LOB elasticity (LOBElast). ESpr is an inverse measure while Depth and LOBElast are direct measures of liquidity. Market activity proxies are: the daily volume in shares $(\mathrm{Vol})\left(/ 10^{4}\right)$; the daily volume in euros $(\mathrm{Vol} €)\left(/ 10^{6}\right)$, and the daily number of trades (Trades). The explanatory variable of interest is the dummy for the postSmart period ("Post-Smart"). We use one period lagged IBEX-35 volatility variable (Volat-1) as a control. We report results for our full sample of 28 stocks (All Stocks) and for the Blue Chips separately. We also report the implied estimated percentage change in each proxy (\% change).

\section{Panel A: HFT}

\begin{tabular}{|c|c|c|c|c|c|c|c|c|}
\hline \multirow[b]{2}{*}{ Variable } & \multicolumn{4}{|c|}{ All stocks } & \multicolumn{4}{|c|}{ Blue chips } \\
\hline & MTMin & $M T V €$ & MTVSh & $\triangle Q M i d$ & MTMin & $M T V €$ & MTVSh & $\triangle Q M i d$ \\
\hline Cons. & $104.52 * * *$ & $0.3331 * * *$ & $0.0528 * * *$ & $5651.39 * * *$ & $224.77 * * *$ & $0.1302 * * *$ & $0.0243 * *$ & $8358.08 * * *$ \\
\hline Post-Smart & $7.58 * * *$ & $0.098 *$ & 0.0121 & $5478.93 * * *$ & $26.81 * * *$ & 0.0101 & -0.0023 & $8948.44 * * *$ \\
\hline Volat-1 & $10.03 * * *$ & $0.0039 * * *$ & -0.0011 & $1587.80 * *$ & $20.21 * * *$ & $0.0005 * * *$ & -0.0002 & $2802.86 * *$ \\
\hline Obs. & 1762 & 1762 & 1762 & 1762 & 441 & 441 & 441 & 441 \\
\hline Adj.-R2 & 0.0073 & 0.0167 & 0.0041 & 0.0842 & 0.0207 & 0.0053 & 0.002 & 0.1051 \\
\hline $\mathrm{F}$ & 50.85 & 27.54 & 11.83 & 216.23 & 27.06 & 2.56 & 3.41 & 86.05 \\
\hline$\%$ change $^{\dagger}$ & $7 \% * * *$ & $29 \% *$ & $23 \%$ & $96 \% * * *$ & $12 \% * * *$ & $8 \%$ & $-9 \%$ & $106 \% * * *$ \\
\hline
\end{tabular}

$\dagger$ Control variable evaluated at the mean 
TABLE 4 (Cont.)

SIBE-Smart: HFT, liquidity, and market activity

Panel B: Liquidity

\begin{tabular}{|c|c|c|c|c|c|c|}
\hline Variable & ESpr & Depth & LOBElast & ESpr & Depth & LOBElast \\
\hline Cons. & $0.0926 * * *$ & $212000 * * *$ & $23400 * * *$ & $0.0489 * * *$ & $462000 * * *$ & $43000 * * *$ \\
\hline Post-Smart & $0.0422 * * *$ & $-47200 * * *$ & $-4040 * * *$ & $0.0153 * * *$ & $-103000 * *$ & $-6760 * * *$ \\
\hline Volat $_{-1}$ & $0.0051 * * *$ & $-8280 * * *$ & $-1130 * * *$ & $0.0034 * * *$ & $-27000 * * *$ & $-2290 * * *$ \\
\hline Obs. & 1762 & 1762 & 1762 & 441 & 441 & 441 \\
\hline Adj.-R2 & 0.0752 & 0.0337 & 0.062 & 0.1827 & 0.0963 & 0.1661 \\
\hline $\mathrm{F}$ & 200.61 & 176.73 & 513.48 & 130.21 & 87.00 & 187.51 \\
\hline$\%$ change $^{\dagger}$ & $46 \% * * *$ & $-22 \% * * *$ & $-17 \% * * *$ & $31 \% * * *$ & $-22 \% * *$ & $-16 \% * * *$ \\
\hline \multicolumn{7}{|c|}{ Panel C: Market activity } \\
\hline Variable & Vol & Vol€ & Trades & Vol & Vol€ & Trades \\
\hline Cons. & $496.06 * * *$ & $48.21 * * *$ & $2572.71 * * *$ & $1446.34 * * *$ & $123.15 * * *$ & $6547.95 * * *$ \\
\hline Post-Smart & $80.99 * * *$ & $-16.69 * * *$ & $303.46 * * *$ & $325.39 * * *$ & -0.52 & $792.66 * * *$ \\
\hline Volat $_{-1}$ & $45.50 * * *$ & $3.90 * * *$ & $219.66 * * *$ & $151.18 * * *$ & $6.28 * * *$ & $552.06 * *$ \\
\hline Obs. & 1762 & 3892 & 3892 & 441 & 441 & 441 \\
\hline Adj.-R2 & 0.0031 & 0.0028 & 0.007 & 0.0168 & 0.0029 & 0.0201 \\
\hline $\mathrm{F}$ & 21.18 & 34.84 & 85.67 & 20.01 & 2.37 & 18.98 \\
\hline$\%$ change $^{\dagger}$ & $16 \% * * *$ & $-35 \% * * *$ & $12 \% * * *$ & $22 \% * * *$ & $-0.42 \%$ & $12 \% * * *$ \\
\hline
\end{tabular}

$* * *, * *, *$ indicates statis tically significant at the $1 \%, 5 \%$ and $10 \%$ level, respectively.

$\dagger$ Control variable evaluated at the mean 


\section{TABLE 5}

SIBE-Smart: realized volatility, price efficiency, realized spread, and price impact

We evaluate the impact of the introduction of the SIBE Smart on volatility and price efficiency (Panel A), and realized spreads and price impacts (Panel B). We compare the "pre-Smart" (March 1, 2012 - April 15, 2012) and "post-Smart" (April 16, 2012 - May 31, 2012) periods. This table presents the estimated coefficients from pooled regressions with double-clustered standard errors. In Panel A, realized volatility (RVolat) is the daily standard deviation of 1-minute trade price returns (x100). Efficiency proxies are the autocorrelation of 1-minute trade price returns (Corr) and the pricing error standard deviation (PrErr), estimated using Hasbrouck (1993). In Panel B, price impact (PrImp) measures the informativeness of trades (adverse selection cost), and the realized spread (RSpr) measures how much of the effective spread is earned by the liquidity provider. Price impact and realized spread are measured over 5-second and 30-second horizons after the trade. The explanatory variable of interest is the dummy for the post-Smart period ("Post-Smart"). We use one period lagged IBEX-35 volatility variable (Volat-1) as a control. We report results for our full sample of 28 stocks (All Stocks) and for the Blue Chips separately. We also report the implied estimated percentage change in each proxy (\% change).

Panel A: Realized volatility and price efficiency

\begin{tabular}{|c|c|c|c|c|c|c|}
\hline \multirow[b]{2}{*}{ Variable } & \multicolumn{3}{|c|}{ All stocks } & \multicolumn{3}{|c|}{ Blue chips } \\
\hline & RVolat & Corr & PrErr & RVolat & Corr & PrErr \\
\hline Cons. & $0.0769 * * *$ & $0.0640 * * *$ & $0.0212 * * *$ & $0.0613 * * *$ & $0.0549 * * *$ & $0.0104 * * *$ \\
\hline Post-Smart & $0.0404 * * *$ & $0.0100 * *$ & $0.0100 * * *$ & $0.0288 * * *$ & $0.0161 * *$ & $0.0025 * * *$ \\
\hline Volat $_{-1}$ & $0.0089 * * *$ & $0.0000 * * *$ & $0.0010 * *$ & $0.0090 * * *$ & $0.0012 * * *$ & $0.0007 * * *$ \\
\hline Obs. & 3892 & 1762 & 1762 & 441 & 441 & 441 \\
\hline Adj. $-R^{2}$ & 0.2877 & 0.0082 & 0.0725 & 0.4387 & 0.0284 & 0.1202 \\
\hline $\mathrm{F}$ & 1400.03 & 7.84 & 194.1182 & 314.29 & 7.88 & 52.7391 \\
\hline$\%$ change $^{\dagger}$ & $52 \% * * *$ & $16 \% * *$ & $47 \% * * *$ & $47 \% * * *$ & $29 \% * *$ & $24 \% * * *$ \\
\hline
\end{tabular}

***,**,* indicates statistically significant at the $1 \%, 5 \%$ and $10 \%$ level, respectively.

$\dagger$ Control variable evaluated at the mean 
TABLE 5 (Cont.)

SIBE-Smart: realized volatility, price efficiency, realized spread, and price impact

Panel B: Realized spread and price impact

\begin{tabular}{|c|c|c|c|c|c|c|c|c|}
\hline Variable & RSpr5 & RSpr30 & PrImp5 & PrImp30 & RSpr5 & RSpr30 & PrImp5 & PrImp30 \\
\hline Cons. & $0.0244 * * *$ & $0.0147 * * *$ & $0.0580 * * *$ & $0.0676 * * *$ & $0.0134 * * *$ & $0.0102 * * *$ & $0.0287 * * *$ & $0.0317 * * *$ \\
\hline Post-Smart & $0.0081 *$ & 0.0069 & $0.0221 * * *$ & $0.0234 * * *$ & -0.0039 & -0.0034 & $0.0151 * * *$ & $0.0146 * * *$ \\
\hline Volat $_{-1}$ & $-0.0023 * * *$ & $-0.0034 * * *$ & $0.0060 * * *$ & $0.0071 * * *$ & $-0.0018 * * *$ & $-0.0020 * * *$ & $0.0046 * * *$ & $0.0049 * * *$ \\
\hline Obs. & 1762 & 1762 & 1762 & 1762 & 441 & 441 & 441 & 441 \\
\hline Adj.-R2 & 0.0076 & 0.0066 & 0.1505 & 0.1227 & 0.0814 & 0.0913 & 0.2981 & 0.2583 \\
\hline $\mathrm{F}$ & 15.15 & 10.26 & 451.49 & 394.01 & 27.60 & 25.97 & 210.87 & 202.4633 \\
\hline$\%$ change $^{\dagger}$ & $33 \% *$ & $47 \%$ & $38 \% * * *$ & $35 \% * * *$ & $-29 \%$ & $-33 \%$ & $52 \% * * *$ & $0.4590642 * * *$ \\
\hline
\end{tabular}

$* * *, * *, *$ indicates statistically significant at the $1 \%, 5 \%$ and $10 \%$ level, respectively.

$\dagger$ Control variable evaluated at the mean 


\section{TABLE 6}

Short-selling bans: comparative effect on HFT activity, liquidity, and market activity

We evaluate the relative impact of the second short-selling ban (SSB2), which affects all stocks, from July 23, 2012 to November 11, 2012 (before colocation is introduced) to the effect of the first short-selling ban (SSB1), which affects only financial stocks (eight in our sample) from August 11, 2011 to February 15, 2012. We test for differences in the level of HFT activity (Panel A), liquidity (Panel B), and market activity (Panel C) in SSB2 versus SSB1. This table presents the estimated coefficients from pooled regressions with double-clustered standard errors. HFT proxies are: message traffic per minute (MTMin); message traffic per euro-volume (MTV€); message traffic per volume in shares (MTVSh), and the number of non-zero quote midpoint changes ( $\triangle Q M i d)$. Liquidity proxies are: effective spread weighted by trade size (x100) (ESpr); timeweighted quoted depth (Depth); and LOB elasticity (LOBElast). ESpr is an inverse measure while Depth and LOBElast are direct measures of liquidity. Market activity proxies are: the daily volume in shares $(\mathrm{Vol})\left(/ 10^{4}\right)$; the daily volume in euros $(\mathrm{Vol} €)\left(/ 10^{6}\right)$, and the daily number of trades $($ Trades). The explanatory variable of interest is the dummy for the second short-sale ban period (SSB2). We report results for our full sample of 28 stocks (All Stocks) and for the Blue Chips separately. We also report the implied estimated percentage change in each proxy (\% change).

\section{Panel A: HFT}

\begin{tabular}{|c|c|c|c|c|c|c|c|c|}
\hline \multirow[b]{2}{*}{ Variable } & \multicolumn{4}{|c|}{ All stocks } & \multicolumn{4}{|c|}{ Blue chips } \\
\hline & MTMin & $M T V €$ & MTVSh & $\triangle Q M i d$ & MTMin & $M T V €$ & MTVSh & $\triangle Q M i d$ \\
\hline Cons. & $97.97 * * *$ & $0.3426 * * *$ & $0.0552 * * *$ & $6027.38 * * *$ & $228.93 * * *$ & $0.1442 * * *$ & $0.0274 * *$ & $11600.00 * * *$ \\
\hline SSB2 & $-75.89 * * *$ & -0.036 & $-0.0106 * *$ & $-2920.00 * * *$ & $-185.13 * * *$ & $-0.0464 * * *$ & $-0.0057 * * *$ & $-5490.00 * *$ \\
\hline Volat $_{-1}$ & $14.04 * * *$ & 0.007 & 0 & $1262.23 * * *$ & $37.39 * * *$ & $0.0041 * *$ & -0.0004 & $2834.54 * * *$ \\
\hline Obs. & 5992 & 5992 & 5992 & 5992 & 1498 & 1498 & 1498 & 1498 \\
\hline Adj.- $\mathrm{R}^{2}$ & 0.0891 & 0.0031 & 0.0047 & 0.05 & 0.2587 & 0.0783 & 0.0081 & 0.0919 \\
\hline $\mathrm{F}$ & 903.74 & 12.62 & 31.49 & 414.51 & 529.69 & 100.99 & 29.24 & 170.53 \\
\hline$\%$ change $^{\dagger}$ & $-77 \% \quad * * *$ & $-11 \%$ & $-19 \% * *$ & $-48 \% * * *$ & $-81 \% * * *$ & $-32 \% \quad * * *$ & $-21 \% * * *$ & $-47 \% * *$ \\
\hline
\end{tabular}

***,**,* indicates statistically significant at the $1 \%, 5 \%$ and $10 \%$ level, respectively.

$\dagger$ Control variable evaluated at the mean 
TABLE 6 (Cont.)

Short-selling bans: comparative effect on HFT activity, liquidity, and market activity

Panel B: Liquidity

\begin{tabular}{|c|c|c|c|c|c|c|}
\hline Variable & ESpr & Depth & LOBElast & ESpr & Depth & LOBElast \\
\hline Cons. & $0.1109 * * *$ & $187000 * * *$ & $20000 * * *$ & $0.0570 * * *$ & $383000 * * *$ & $36000 * * *$ \\
\hline SSB2 & $0.0571 * * *$ & $-40100 * *$ & $-3800 * * *$ & $0.0252 * * *$ & $-101000 *$ & $-7910 * * *$ \\
\hline Volat $_{-1}$ & $0.0117 * * *$ & -4460 & $-1020 * * *$ & $0.0057 * * *$ & -13700 & $-1760 * * *$ \\
\hline Obs. & 5992 & 5992 & 5992 & 1498 & 1498 & 1498 \\
\hline Adj.-R2 & 0.0969 & 0.0162 & 0.0538 & 0.1864 & 0.048 & 0.1653 \\
\hline $\mathrm{F}$ & 676.91 & 123.49 & 848.03 & 278.82 & 61.70 & 398.39 \\
\hline$\%$ change $^{\dagger}$ & $51 \% * * *$ & $-21 \% * *$ & $-19 \% * * *$ & $44 \% * * *$ & $-26 \% *$ & $-22 \% * * *$ \\
\hline \multicolumn{7}{|c|}{ Panel C: Market activity } \\
\hline Variable & Vol & Vol€ & Trades & Vol & Vol€ & Trades \\
\hline Cons. & $348.28 * * *$ & $33.87 * * *$ & $2149.84 * * *$ & $1128.20 * * *$ & $108.86 * * *$ & $5317.02 * * *$ \\
\hline SSB2 & -58.07 & $-14.97 * * *$ & $-726.31 * * *$ & $-279.58 * * *$ & $-47.79 * * *$ & $-1790.00 * * *$ \\
\hline Volat $_{-1}$ & $52.06 * * *$ & $2.99 * * *$ & $200.83 * * *$ & $175.18 * * *$ & $10.41 * * *$ & $631.30 * * *$ \\
\hline Obs. & 5992 & 5992 & 5992 & 1498 & 1498 & 1498 \\
\hline Adj.-R2 & 0.0063 & 0.0158 & 0.0213 & 0.0331 & 0.0839 & 0.0892 \\
\hline $\mathrm{F}$ & 93.26 & 208.82 & 299.21 & 86.63 & 161.42 & 176.03 \\
\hline$\%$ change $^{\dagger}$ & $-17 \%$ & $-44 \% * * *$ & $-0.34 * * *$ & $-25 \% * * *$ & $-44 \% * * *$ & $-0.34 * * *$ \\
\hline
\end{tabular}

$* * *, * * *$ indicates statistically significant at the $1 \%, 5 \%$ and $10 \%$ level, respectively.

$\dagger$ Control variable evaluated at the mean 


\section{TABLE 7}

Short-selling bans: Comparative effect on realized volatility, price efficiency, realized spreads, and price impacts

We evaluate the relative impact of the second short-selling ban (SSB2), which affects all stocks, from July 23, 2012 to November 11, 2012 (before colocation is introduced) to the effect of the first short-selling ban (SSB1), which affects only financial stocks (eight in our sample) from August 11, 2011 to February 15, 2012. We test for differences in volatility and price efficiency (Panel A), and realized spreads and price impacts (Panel B) between SSB2 and SSB1. This table presents the estimated coefficients from pooled regressions with double-clustered standard errors. In Panel A, realized volatility (RVolat) is the daily standard deviation of 1-minute trade price returns (x100). Efficiency proxies are the autocorrelation of 1-minute trade price returns (Corr) and the pricing error standard deviation (PrErr), estimated using Hasbrouck (1993). In Panel B, price impact (PrImp) measures the informativeness of trades (adverse selection cost), and the realized spread (RSpr) measures how much of the effective spread is earned by the liquidity provider. Price impact and realized spread are measured over 5-second and 30-second horizons after the trade. The explanatory variable of interest is the dummy for the second short-sale ban period (SSB2). We report results for our full sample of 28 stocks (All Stocks) and for the Blue Chips separately. We also report the implied estimated percentage change in each proxy (\% change).

Panel A: Realized volatility and price efficiency

\begin{tabular}{|c|c|c|c|c|c|c|}
\hline & \multicolumn{3}{|c|}{ All stocks } & \multicolumn{3}{|c|}{ Blue chips } \\
\hline Variable & RVolat & Corr & PrErr & RVolat & Corr & PrErr \\
\hline Cons. & $0.0815 * * *$ & $0.0638 * * *$ & $0.0254 * * *$ & $0.0647 * * *$ & $0.0562 * * *$ & $0.0116 * * *$ \\
\hline SSB2 & 0.0058 & $0.0085 * * *$ & $0.0111 * * *$ & 0.0081 & 0.0039 & $0.0060 * * *$ \\
\hline Volat $_{-1}$ & $0.0171 * * *$ & 0.0010 & $0.0036 * * *$ & $0.0153 * * *$ & $0.0035 * *$ & $0.0018 * * *$ \\
\hline Obs. & 5992 & 5992 & 5988 & 1498 & 1498 & 1498 \\
\hline Adj.- $\mathrm{R}^{2}$ & 0.2129 & 0.0059 & 0.0671 & 0.3596 & 0.0101 & 0.212 \\
\hline $\mathrm{F}$ & 1240.85 & 18.00 & 420.58 & 467.82 & 7.73 & 268.51 \\
\hline$\%$ change $^{\dagger}$ & $7 \%$ & $13 \% * * *$ & $44 \% * * *$ & $12 \%$ & $7 \%$ & $52 \% * * *$ \\
\hline
\end{tabular}

***,**,* indicates statistically significant at the $1 \%, 5 \%$ and $10 \%$ level, respectively.

$\dagger$ Control variable evaluated at the mean 
TABLE 7 (Cont.)

Short-selling bans: Comparative effect on realized volatility, price efficiency, realized spreads, and price impacts

Panel B: Realized spread and price impact

\begin{tabular}{|c|c|c|c|c|c|c|c|c|}
\hline Variable & RSpr5 & RSpr30 & PrImp5 & PrImp30 & RSpr5 & RSpr30 & PrImp5 & PrImp30 \\
\hline Cons. & $0.0425 * * *$ & $0.0331 * * *$ & $0.0549 * * *$ & $0.0641 * * *$ & $0.0173 * * *$ & $0.0124 * * *$ & $0.0325 * * *$ & $0.0374 * * *$ \\
\hline SSB2 & $0.0205 * * *$ & $0.0188 * * *$ & $0.0140 * * *$ & $0.0156 * * *$ & $0.0086 * *$ & 0.0043 & $0.0108 * * *$ & $0.015 * * *$ \\
\hline Volat $_{-1}$ & 0.0015 & -0.0003 & $0.0089 * * *$ & $0.0107 * * *$ & -0.0005 & -0.001 & $0.0053 * * *$ & $0.0058 * * *$ \\
\hline Obs. & 5992 & 5992 & 5992 & 5992 & 1498 & 1498 & 1498 & 1498 \\
\hline Adj.- $R^{2}$ & 0.0383 & 0.0308 & 0.1098 & 0.1077 & 0.0769 & 0.0266 & 0.1835 & 0.1937 \\
\hline $\mathrm{F}$ & 256.45 & 173.38 & 751.85 & 724.63 & 79.55 & 23.65 & 286.03 & 299.62 \\
\hline$\%$ change $^{\dagger}$ & $48 \% * * *$ & $57 \% * * *$ & $26 \% * * *$ & $24 \% * * *$ & $50 \% * *$ & $35 \%$ & $33 \% * * *$ & $40 \% * * *$ \\
\hline
\end{tabular}

$* * *, * *, *$ indicates statistically significant at the $1 \%, 5 \%$ and $10 \%$ level, respectively.

$\dagger$ Control variable evaluated at the mean 


\section{TABLE 8}

\section{Colocation: HFT, liquidity, and market activity}

Colocation services are introduced on the SSE on November 12, 2012, with an overlapping short-selling ban period that starts on July 23 , 2012 and ends on January 31 , 2013. We test for differences in the level of HFT (Panel A), liquidity (Panel B), and market activity (Panel C) before and after colocation. First, we compare the "pre-colocation" period (July 23, 2013 - November 11, 2012), a time with banned short-selling and no colocation, with the "post-colocation" period (November 12, 2012 - January 31, 2013), a time with banned short-selling and colocation. Second, we compare the "pre-ban" period (April 16, 2012 - July 22, 2012), a time with no ban and no colocation, with the "post-ban" period (February 1, 2013 - June 31, 2013), a time with no ban but with colocation. This table presents the estimated coefficients from pooled regressions with double-clustered standard errors. HFT proxies are: message traffic per minute (MTMin); message traffic per euro-volume (MTV€); message traffic per volume in shares (MTVSh), and the number of non-zero quote midpoint changes ( $\triangle Q M i d)$. Liquidity proxies are: effective spread weighted by trade size (x100) (ESpr); time-weighted quoted depth (Depth); and LOB elasticity (LOBElast). ESpr is an inverse measure while Depth and LOBElast are direct measures of liquidity. Market activity proxies are: the daily volume in shares $(\mathrm{Vol})\left(/ 10^{4}\right)$; the daily volume in euros $(\mathrm{Vol} €)\left(/ 10^{6}\right)$, and the daily number of trades (Trades). The explanatory variables of interest are the dummy variables for Post- vs pre-colocation and Post- vs pre-ban. We report results for our full sample of 28 stocks (All Stocks) and for the Blue Chips separately. We also report the implied estimated percentage change in each proxy (\% change).

\section{Panel A: HFT}

\begin{tabular}{|c|c|c|c|c|c|c|c|c|c|c|}
\hline \multirow[b]{2}{*}{ Variable } & \multicolumn{4}{|c|}{ All stocks } & \multirow[b]{2}{*}{ Obs. } & \multicolumn{4}{|c|}{ Blue chips } & \multirow[b]{2}{*}{ Obs. } \\
\hline & MTMin & $M T V €$ & MTVSh & $\triangle Q M i d$ & & MTMin & $M T V €$ & MTVSh & $\triangle$ QMid & \\
\hline Cons. & $39.17 * * *$ & $0.2971 * * *$ & $0.0445 * * *$ & $3322.88 * * *$ & 3808 & $94.16 * * *$ & $0.099 * * *$ & $0.0206 *$ & $7366.46 * *$ & 952 \\
\hline Post- vs. pre-colocation & -3.00 & $-0.1245 * * *$ & $-0.0158 * * *$ & $-2200.00 * * *$ & & -5.01 & -0.0106 & -0.0031 & $-4630.00 * * *$ & \\
\hline Volat $_{-1}$ & $7.03 * * *$ & 0.0109 & 0.0000 & $1173.18 * * *$ & & $16.75 * * *$ & 0.0036 & $0.0000 * * *$ & $2334.67 * * *$ & \\
\hline Adj.-R2 & 0.0206 & 0.0312 & 0.0159 & 0.1055 & & 0.0511 & 0.0141 & 0.003 & 0.1794 & \\
\hline$\%$ change $^{\dagger}$ & $-8 \%$ & $-42 \% * * *$ & $-36 \% * * *$ & $-66 \% * * *$ & & $-5 \%$ & $-11 \%$ & $-15 \%$ & $-62 \% * * *$ & \\
\hline Cons. & $106.73 * * *$ & $0.429 * * *$ & $0.06 * * *$ & $12300.00 * * *$ & 4816 & $222.88 * * *$ & $0.1359 * * *$ & $0.0235 *$ & $18000.00 * * *$ & 1204 \\
\hline Post- vs. pre-ban & $-22.34 * *$ & $-0.148 * *$ & -0.0155 & $-8920.00 * * *$ & & -26.27 & 0.007 & $0.0084 *$ & $-11600.00 * * *$ & \\
\hline Volat_1 $_{1}$ & $8.46 * * *$ & $0.0125 * *$ & $0.0021 * * *$ & $1129.20 * * *$ & & $19.22 * * *$ & 0.0011 & $-0.0007 * * *$ & $1966.87 * *$ & \\
\hline Adj.-R2 & 0.0168 & 0.0225 & 0.0088 & 0.1953 & & 0.0262 & 0.0016 & 0.0119 & 0.199 & \\
\hline$\%$ change $^{\dagger}$ & $-21 \% * *$ & $-34 \% * *$ & $-26 \%$ & $-72 \% * * *$ & & $-12 \%$ & $5 \%$ & $36 \% *$ & $-64 \% * * *$ & \\
\hline
\end{tabular}

$* * *, * *, *$ indicates statistically significant at the $1 \%, 5 \%$ and $10 \%$ level, respectively.

$\dagger$ Control variable evaluated at the mean 
TABLE 8 (Cont.)

Colocation: HFT, liquidity, and market activity

Panel B: Liquidity

\begin{tabular}{|c|c|c|c|c|c|c|c|c|}
\hline Variable & ESpr & Depth & LOBElast & Obs. & ESpr & Depth & LOBElast & Obs. \\
\hline Cons. & $0.1056 * * *$ & $252000 * * *$ & $23000 * * *$ & 3808 & $0.0590 * * *$ & $452000 * * *$ & $39700 * * *$ & 952 \\
\hline Post- vs. pre-colocation & $0.0424 * * *$ & $7189 * *$ & $-2820 * * *$ & & $0.0148 * *$ & $85400 *$ & $-3660 * * *$ & \\
\hline Volat $_{-1}$ & $0.0090 * * *$ & -28700 & $-1350 * * *$ & & $0.0034 * * *$ & -54700 & $-2540 * *$ & \\
\hline$\%$ change $^{\dagger}$ & $40 \% * * *$ & $3 \% * *$ & $-12 \% * * *$ & & $25 \% * *$ & $19 \% *$ & $-9 \% * * *$ & \\
\hline Cons. & $0.1345 * * *$ & $150000 * * *$ & $17600 * * *$ & 4816 & $0.0704 * * *$ & $276000 * * *$ & $32000 * * *$ & 1204 \\
\hline Post- vs. pre-ban & $-0.0224 * * *$ & $64800 * *$ & $4117 * * *$ & & $-0.0073 *$ & $99900 * *$ & $4822 * * *$ & \\
\hline Volat $_{-1}$ & $0.0054 * * *$ & $-9010 * * *$ & $-635 * * *$ & & 0.0012 & $-14100 * *$ & $-1000 * * *$ & \\
\hline Adj.-R2 & 0.0272 & 0.0358 & 0.0465 & & 0.0308 & 0.0865 & 0.0551 & \\
\hline$\%$ change $^{\dagger}$ & $-17 \% * * *$ & $43 \% * *$ & $23 \% * * *$ & & $-10 \% *$ & $36 \% * *$ & $15 \% * * *$ & \\
\hline \multicolumn{9}{|c|}{ Panel C: Market activity } \\
\hline Variable & Variable $\mathrm{Vol}$ & Vol€ & Trades & Obs. & Vol & Vol€ & Trades & Obs. \\
\hline Cons. & $295.68 * * *$ & $20.92 * * *$ & $1397.90 * * *$ & 3808 & $832.26 * *$ & $67.23 * * *$ & $3529.15 * * *$ & 952 \\
\hline Post- vs. pre-colocation & 200.08 & 1.03 & 76.79 & & $-122.19 * *$ & -4.92 & -284.55 & \\
\hline Adj.-R2 & 0.0056 & 0.0031 & 0.0118 & & 0.043 & 0.0277 & 0.0701 & \\
\hline$\%$ change $^{\dagger}$ & $67 \%$ & $5 \%$ & $5 \%$ & & $-15 \% * *$ & $-7 \%$ & $-8 \%$ & \\
\hline Cons. & $591.36 * * *$ & $35.96 * * *$ & $2870.87 * * *$ & 4816 & $1862.84 * * *$ & $116.50 * * *$ & $7276.41 * * *$ & 1204 \\
\hline Post- vs. pre-ban & 16.55 & $-4.40 * * *$ & $-538.59 * * *$ & & $-635.33 * *$ & $-22.79 * * *$ & $-1870.00 * * *$ & \\
\hline Volat $_{1}$ & $27.88 * * *$ & $1.40 * * *$ & $156.01 * * *$ & & $78.66 * * *$ & $4.66 * * *$ & $411.29 * * *$ & \\
\hline Adj.-R2 & 0.0044 & 0.0030 & 0.0067 & & 0.0388 & 0.0246 & 0.0565 & \\
\hline$\%$ change $^{\dagger}$ & $3 \%$ & $-12 \% * * *$ & $-19 \% * * *$ & & $-34 \% * *$ & $-20 \% * * *$ & $-26 \% * * *$ & \\
\hline
\end{tabular}

$* * *, * *, *$ indicates statistically significant at the $1 \%, 5 \%$ and $10 \%$ level, respectively.

$\dagger$ Control variable evaluated at the mean 


\section{TABLE 9}

\section{Colocation: realized volatility, price efficiency, realized spreads, and price impacts}

Colocation services are introduced on the SSE on November 12, 2012, with an overlapping short-selling ban period that starts on July 23, 2012 and ends on January 31, 2013. We test for differences in realized volatility and price efficiency (Panel A), and realized spreads and price impacts (Panel B) before and after colocation. First, we compare the "pre-colocation" period (July 23, 2013 - November 11, 2012), a time with banned short-selling and no colocation, with the "post-colocation" period (November 12, 2012 January 31, 2013), a time with banned short-selling and colocation. Second, we compare the "pre-ban" period (April 16, 2012 - July 22, 2012), a time with no ban and no colocation, with the "post-ban" period (February 1, 2013 - June 31, 2013), a time with no ban but with colocation. This table presents the estimated coefficients from pooled regressions with double-clustered standard errors. In Panel A, realized volatility (RVolat) is the daily standard deviation of 1-minute trade price returns (x100). Efficiency proxies are the autocorrelation of 1-minute trade price returns (Corr) and the pricing error standard deviation (PrErr), estimated using Hasbrouck (1993). In Panel B, price impact (PrImp) measures the informativeness of trades (adverse selection cost), and the realized spread (RSpr) measures how much of the effective spread is earned by the liquidity provider. Price impact and realized spread are measured over 5-second and 30-second horizons after the trade. The explanatory variables of interest are the dummy variables for Post- vs pre-colocation and Post- vs pre-ban. We report results for our full sample of 28 stocks (All Stocks) and for the Blue Chips separately. We also report the implied estimated percentage change in each proxy (\% change).

Panel A: Realized volatility and price efficiency

\begin{tabular}{|c|c|c|c|c|c|c|c|}
\hline \multirow[b]{2}{*}{ Variable } & \multicolumn{3}{|c|}{ All stocks } & \multicolumn{4}{|c|}{ Blue chips } \\
\hline & RVolat & Corr & PrErr & RVolat & Corr & PrErr & Obs. \\
\hline Cons. & $0.0890 * * *$ & $0.0700 * * *$ & $0.0362 * * *$ & $0.0757 * * *$ & $0.0555 * * *$ & $0.0173 * * *$ & 952 \\
\hline Post- vs. pre-colocation & $-0.0133 * * *$ & $0.0131 * * *$ & $-0.0053 * * *$ & $-0.0228 * * *$ & $0.0096 * *$ & -0.0021 & \\
\hline Volat $_{-1}$ & $0.0164 * * *$ & 0.0020 & $0.0038 * * *$ & $0.0141 * * *$ & $0.0053 * * *$ & $0.0020 * * *$ & \\
\hline Adj.-R2 & 0.2179 & 0.0084 & 0.0533 & 0.5306 & 0.0151 & 0.1025 & \\
\hline$\%$ change $^{\dagger}$ & $-15 \% * * *$ & $19 \% * * *$ & $-15 \% * * *$ & $-30 \% * * *$ & $17 \% * *$ & $-12 \%$ & \\
\hline Cons. & $0.1182 * * *$ & $0.0680 * * *$ & $0.0328 * * *$ & $0.0968 * * *$ & $0.0659 * * *$ & $0.0164 * * *$ & 1204 \\
\hline Post- vs. pre-ban & $-0.0338 * * *$ & 0.0021 & $-0.0100 * * *$ & $-0.026 * * *$ & -0.0016 & $-0.0039 * * *$ & \\
\hline Volat $_{-1}$ & $0.0073 * * *$ & $0.0020 *$ & $0.0009 * * *$ & $0.006 * * *$ & 0.0022 & -0.0001 & \\
\hline Adj.-R2 & 0.2467 & 0.0009 & 0.0659 & 0.4112 & 0.0026 & 0.0921 & \\
\hline$\%$ change $^{\dagger}$ & $-29 \% * * *$ & $3 \%$ & $-30 \% * * *$ & $-27 \% * * *$ & $-2 \%$ & $-24 \% * * *$ & \\
\hline
\end{tabular}

$* * *, * * * *$ indicates statistically significant at the $1 \%, 5 \%$ and $10 \%$ level, respectively

$\dagger$ Control variable evaluated at the mean 
TABLE 9 (Cont.)

Colocation: realized volatility, price efficiency, realized spread, and price impact

\begin{tabular}{|c|c|c|c|c|c|c|c|c|c|}
\hline Variable & RSpr5 & RSpr30 & PrImp5 & PrImp30 & RSpr5 & RSpr30 & PrImp5 & PrImp30 & Obs. \\
\hline Cons. & $0.0617 * * *$ & $0.0512 * * *$ & $0.0723 * * *$ & $0.0827 * * *$ & $0.0271 * * *$ & $0.0191 * * *$ & $0.0450 * * *$ & $0.0528 * * *$ & 952 \\
\hline Post- vs. pre-colocation & -0.0018 & -0.0016 & $-0.0191 * * *$ & $-0.0193 * * *$ & 0.0047 & $0.0062 * *$ & $-0.0160 * * *$ & $-0.0174 * * *$ & \\
\hline Volat $_{-1}$ & 0.002 & 0.0000 & $0.0075 * * *$ & $0.0095 * * *$ & -0.0009 & $-0.0020 * *$ & $0.0046 * * *$ & $0.0056 * * *$ & \\
\hline Adj.-R2 & 0.0042 & 0.0003 & 0.1285 & 0.1207 & 0.0274 & 0.0622 & 0.2841 & 0.2636 & \\
\hline$\%$ change $^{\dagger}$ & $-3 \%$ & $-3 \%$ & $-26 \% * * *$ & $-23 \% * * *$ & $17 \%$ & $33 \% * *$ & $-35 \% * * *$ & $-33 \% * * *$ & \\
\hline Cons. & $0.0308 * * *$ & $0.0208 * * *$ & $0.0796 * * *$ & $0.0895 * * *$ & $0.0097 * * *$ & $0.0059 * * *$ & $0.0467 * * *$ & $0.0504 * * *$ & 1204 \\
\hline Post- vs. pre-ban & 0.0019 & 0.0001 & $-0.0212 * * *$ & $-0.0194 * * *$ & $0.0034 * *$ & 0.0009 & $-0.0093 * * *$ & $-0.0068 * * *$ & \\
\hline Volat $_{-1}$ & -0.0005 & $-0.0017 * *$ & $0.0051 * * *$ & $0.0063 * * *$ & $-0.0014 * * *$ & $-0.0014 * * *$ & $0.0031 * * *$ & $0.0032 * * *$ & \\
\hline Adj.-R2 & 0.0011 & 0.0023 & 0.1355 & 0.0951 & 0.0602 & 0.0249 & 0.1594 & 0.088 & \\
\hline$\%$ change $^{\dagger}$ & $6 \%$ & $0 \%$ & $-27 \% * * *$ & $-22 \% * * *$ & $35 \% * *$ & $15 \%$ & $-20 \% * * *$ & $-13 \% * * *$ & \\
\hline
\end{tabular}

$* * *, * *, *$ indicates statistically significant at the $1 \%, 5 \%$ and $10 \%$ level, respectively.

$\dagger$ Control variable evaluated at the mean 